\title{
El otro lado del
}

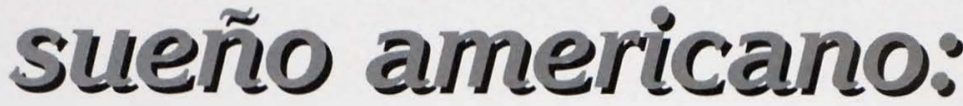

Por: Fina Viegas Guillem

$\mathrm{L}$ as migraciones son un fenómeno que está siendo protagonista desde el último cuarto del siglo $\mathrm{XX}$ de cambios socio-culturales muy profundos en este mundo en el que vivimos. Ahora son los países desarrollados $\mathrm{cl}$ destino que escogen por distintos motivos millones de personas. Las portadas de los periódicos y las noticias de la televisión de los paises del Norte dan idea de un fenómeno que es el germen de una nueva sociedad en esa parte del mundo. Es importante verlo también desde la otra cara, la de los paises de origen de los migrantes, ésta es nuestra incención, of recer un panorama sobre uno de los aspecros menos conocidos de las migraciones, las deportaciones, con un enfoque desde El Salvador.

Sin embargo, la falta de tradición académica y lo que parece como una única vertiente de interpretación económica de las migraciones hace que se conozca mucho menos de las consecuencias socio-culturales desde los paises de origen de los migrantes.

Existe una imagen "oficial" dcl salvadoreño migrante, difundida y aceptada por los medios. Es el hermano lejano exitoso, trabajador, "vivo", que remesa a sus seres queridos en el Pulgarcito de América. Es una imagen positiva apuntalada, con viajes oficiales de los miembros del gobierno a sus compatriotas en el Norte. Con los recientes terremotos hemos visto a nuestros gobernantes realizar pactos internacionales y reunirse con lideres de las asociaciones de emigrantes salvadoreños en otros paises para apoyar la reconstrucción del pais.

Estamos, pues, acostumbrados a identificar las migraciones en un sentido positivo. Peroexiste otro la do del sueño americano. En este contexto de éxito y de poder que poseen las migraciones aparece un grupo de personas que parece representar todo lo contrario, esto es, la frustración y el fracaso de un intento fallido cuando las personas son devueltas a El Salvador por motivos distintos. Son los retornados involuntarios que regresan sin haber escogido libremente su vuelta. Son un grupo de personas cada vez más abundante conforme se están endureciendo las leyes migratorias y cerrando las fronteras.

Los deportados son como los retornados, agentes de cambio cultural. Ellos traen consigo actitudes nuevas y visiones distintas de su propio pais. La estancia en EEUU les ha proporcionado experiencia valiosa que por términos de comparación los hace más críticos en muchos aspectos.

El universo de personas deportadas es amplio. Llegan desde México y Guatemala por tierra, pero el número más amplio llega sin duda por avión desde EEUU. Para este último rubro de personas que llega desde Estados Unidos se implantó el Programa Bienvenido a Casa. Dicho programa cuenta con estadísticas acerca de la situación sociocultural de los "muchachos" como les llaman los encargados.

El fracaso que representan para la sociedad se ve resumido en una frase "No la supiste hacer". En resumidas cuentas la persona deportada trunca, con el retorno involuntario, las posibilidades de su propio sueño y quizás el de toda una familia que habia puesto sus esperanzas en él y automáticamente pasa a ser identificado como delincuente.

En este trabajo pretendemos arrojar luz sobre uno de los aspectos menos conocidos de los procesos migratorios en este país, el de los deportados, que engloban, junto con los desaparecidos, el lado menos difundido de las "exitosas migraciones internacionales en El Salvador".

\section{Las migraciones en el contexto internacional}

Tecesariamente en la aproximación al conocimiento de las migraciones internacionales ocurridas en este Pulgarcito de América, hemos de tener en cuenta el proceso global migratorio que ocurre en todo nuestro planeta. Con ello of recerémos la necesaria perspectiva universal importante para dimensionar el problema.

Alejándonos de la región centroamericana observamos cómo las migraciones internacionales son noticia también 
El otro lado del sueño americano

en otras partes del mundo. En definitiva, los medios de comunicación recogen, la mayor parte de veces, de la punta del iceberg este traslado masivo de personas. La mayor parte de las noticias hacen referencia a la descomposición de bandas de polleros o los nuevos traficantes de personas o el descubrimiento de polizones migrantes en barcos, camiones etc.

Es bien sabido cómo en la uiltima década del siglo (y del milenio pasado), el problema de las migraciones ha ido in crescendo. Se pueden identificar tres grandes corrientes de migración. La primera gran corriente hace referencia al desplazamiento de los pobres, los desempleados y en gran medida los excluidos de los mercados de trabajo u oferta laboral, que sólo rienen acceso a los sectores informales o más precarios de la economía de las sociedades receptoras. Los migrantes marchan a los paises desarrollados en busca de una mejor calidad de vida.

La segunda corriente migratoria hace referencia al desplazamiento de los cuadros técnicos y profesionales que se movilizan en forma cada vez más fluida en mercados multinacionales, formales y muy exclusivos.

La tercera y úlcima gran corriente es la de los refugiados por causas políticas o luchas étnico-tribales.

La que nos interesa aquí es la primera de todas ellas, en la que se incluye más o menos entre un 20 y un 25 por ciento de la población salvadoreña que opta por marcharse fundamentalmente a Estados Unidos y Canadá. La migración de los pobres implica un orden mundial aceptado internacionalmente. Las migraciones y sus protagonistas, los migrantes, "son una prueba de la miseria en el seno de la riqueza, del autoritarismo en un mundo que quiere ser democrático: del prejuicio en sociedades pretendidamente multiculturales. Una prueba concreta, constituida por personas que en su movilización demuestran la evidencia de un orden no sostenible, $y$ por eso, amenazante para el futuro de la humanidad".

El tono de gravedad con que se trata el fenómeno de las migraciones desde los paises desarrollados no parece tener una explicación sencilla cuando analizamos algunos aspectos concretos como el número de migrantes. Cuantitativamente cl número de migrantes es el doble que a comienzos de siglo, mientras que la población se ha multiplicados por cuatro.

Los puntos de destino de las migraciones internacionales mundiales continua siendo los Estados Unidos y Canadá; América del Norte; los paisesárabes productores de petróleo; Inglaterra. Holanda. Francia, Alcmania, Bélgica o Suiza en Europa occidental; los paises nórdicos, Australia, Argentina, Venezucla. Costa Rica en América Latina o la Repuiblica Sudafricana en el continente af ricano.

Han aparecido nuevos paises de descino como España, Italia o Japón inexistentes a principios del siglo XX. De igual forma también han aparecido nuevos focos de emigración como países de Europa del Este y otros sudamericanos.

Entonces, desde el punto de vista cualitativo y de la dirección de los flujos de las grandes tendencias no han variado mucho.

Para Lelio Mármora, de la Organización Internacional de las Migraciones, la explicación de la preocupación de los paises receptores de migrantes radica en aspectos politicos $y$ culturales. Para él las migraciones son vistas cada vez más como una amenaza por parte los países receptores y por los

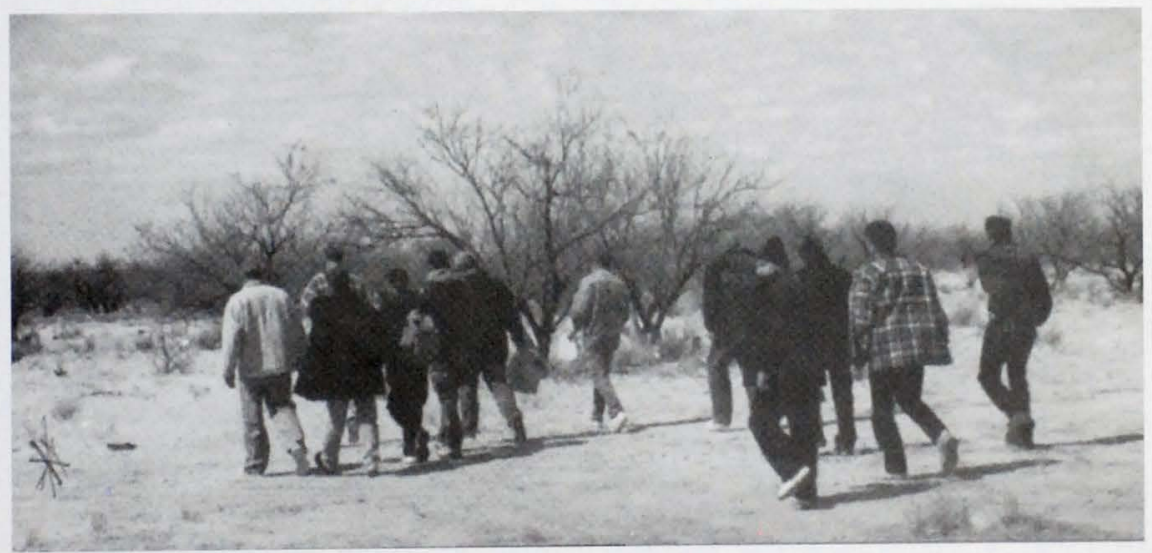


migrantes como la única opción viable para la sobrevivencia personal, familiar e incluso social.

Sin embargo, las migraciones masivas de principios del siglo $X X$ y de la posiguerra eran vistas como una redistribución de los recursos humanos. Las actuales se encienden como una redistribución de la pobreza desde los paises desarrollados. La respuesta a la llegada masiva de personas a estos paises es la restricción por todos los medios al flujo de los migrantes. Esto en un contexto en el que los principios dominantes de la economía de mercado propician la libre circulación de capital y productos. Las medidas contra la migración suponen pues una contradicción a la libre circulación de los factores económicos al mantener sujeto a uno de ellos, el factor trabajo, frente a la creciente movilidad de los demás factores.

Por otra parte, existen otros factores políticos a tener en cuenta para explicar la consideración como problema de la inmigración en los paises desarrollados. Políticamente, tras la caida del muro de Berlin y del bloque socialista cambió la visión de los emigrantes de la zona socialista. La llegada en ese momento de inmigrantes procedentes de esos lugares se consideraba en sentido positivo, al interpretarse como una vía de escape a los regímenes socialistas. Después, trasla caida politica de los regimenes y la crisis económica, muchos ciudadanos de Europa del Este han optado por distintas vías de escapar de la pobreza y de la falta de oportunidades. En estos momentos ya no son tan bien recibidos los inmigrantes de Europa del Este.

En este mundo cada vez más globalizado los medios de comunicación nos informan de lo que pasa al otro lado del mundo inmediatamente. A través de los noticieros de televisión o por las nuevas tecnologias de Internet podemos observar las comodidades y el lujo en el que vive sólo una parte reducida de la humanidad, mientras que otros, los habitantes de los paises desarrollados ven en los inmigrantes un peligro para el sistema establecido. El ciudadano de a pie de los paises receptores ve en los inmigrantes un chivo expiatorio a quien culpar por la falta de empleos. De la misma manera por la inseguridad en las calles y del aumento de la pobreza en los países ricos. Para los políticos de estos mismos países pueden llegar a ser utilizados para ganar votos, entre los sectores de electores reacios a la inmigración, con el atractivo politico de que los inmigrantes no suelen tener el derecho a voto en los países de residencia.

Esta percepción se incrementa con el creciente problema del tráfico ilegal de personas que no es más que el tráfico con la miseria humana. Los inmigrantes, ante el exhaustivo control de las fronteras se ven obligados a pagar cantidades exorbitantes para atravesar los Iímites fron terizos en circunstancias muchas de las veces peligrosas para su salud.
El comercio ilegal de inmigrantes está relacionado con redes de prostitución infantil y de mujeres: y en otros casos con objerivos en la adopción ilegal o comercio de órganos.

Los gobiernos, con su restricción a la llegada de inmigrantes y el bloqueo realizado en las fronteras, enfatizan la imagen de delincuente de los inmigrantes indocumentados. Aunque por otra parte, a pesar de la persecución indiscriminada que en muchas fronteras se está realizando conera los inmigrantes no parece que se haya debilitado la delincuencia organizada en torno a ellos.

Las actuaciones de los gobiernos van encaminadas a mantener medidas restricrivas a la migración, perode carácter nacional. Por lo tanto, están tratando de solucionar un problema que tiene unas raíces macro, vinculadas a las relaciones internacionales en las que intervienen factores politicos, económicos y culturales en la nueva sociedad globalizada.

\section{Los derechos humanos de los migrantes}

Como bien es sabido, los derechos humanos son de rodos y cada uno de las personas, los cuales son imposibles de erradicar o suspender temporal o definitivamente. Por ello, los migrantes a pesar de transitar indocumentados y traspasar las fronteras nacionales de forma fraudulenta continúan manteniendo plenos sus derechos humanos. En el contexto internacional de las migraciones es importante tener en cuenta este punto porque los migrantes son vulnerables a todo tipo de acciones delictivas.

El primer ámbito en el que los migrantes ven violados sus derechos humanos es en su derecho a no migrar, su derecho a desarrollarse plenamente en el lugar donde nacieron. Por eso mismo a los migrantes, antes incluso de serlo, ya ven violado su derecho a vivir una vida digna fundamentalmente. Por supuesto que en el caso de los desplazados por motivos de guerra o genocidio esta relación se hace estrecha y directa.

Carecen Internacional, reproduce una frase de los monjes scalibrinianos que dice: "Migrar no es un delito, delito es lo que causa la migración”. Hace referencia a la idea de que los migrantes no son culpables de la migración sino toda una situación en la que viven o sobreviven en sus paises de origen.

Por supuesto, que el ángulo más habitual a la hora de analizar las violaciones de derechos humanos a los migrantes son todos los delitos de los cuales son objeto tanto en los países de tránsito como en el de destino. Todos hemos oído hablar de los robos y violaciones de salvadoreños en Guatemala y México, a menudo esta imagen sale en las 
norici.us de la prensa o la televisión. Otro punto fundamental de la violación de los derechos humanos de los migranies es en los puíses de destino donde hajo amenazas de ser denunciados a las instancias migratorias trabajan en condiciones indignas tanto en Europa como en Estados Unidos.

\section{Las migraciones en El Salvador}

$\mathrm{H}$

asta los anos ochenta, la migración internacional fuera de la región Centroamericana estaba reservada a las capas sociale's privilegiadas y medias altas que viajaban a oeroslugares por varios motives. A partir de estos momentos el perfil de los migrantes varía cualicativamente comenzando a emigrar a otros paises, sobretodo listados Unidos, los sectores sociales inferiores. Comienza a establecerse una relación que continua hasta cl momento en la que se asocia la migración "legal" a las capas medias y altas y la "ilcgal" a las bajas.

La migración "legal" se realiza por los pasos establecidos por los países para auravesar las fronceras y con la presentación debida de documentos. En este caso las vias son por ticrra o por avión ya que rodos los trámites sc realizan por las vías rurinarias. La migración "ilegal", sin cmbargo, no pasa cstos controles migratorios y en muchos de los casos aunque sí posea visa para entrar a Estados Unidos permanece de forma ilega! sin que las autoridades correspondientes lo conozcan. Esta última es la que nos interesa en este estudio $y$ la que conforma el grueso de la migración internacional de El Salvador.

Existen varios estudios que han intentado sistematizar el perfil del migrante salvadoreño que deja su pais para irse a trabajar a los Estados Unidos. Las características principales son que se trata fundamentalmente de migración urbana, aunque se está incrementando el porecentaje de población de origen rural. El grado de escolaridad medio de los migrantessalvadoreños es menor al de los mexicanos y otros centroamericanos en las mismas condiciones. La proporción de mujeres es mayor de lo que se piensa y se ha incrementado con el tiempo.

Estc ripo de migración ha sido calificada como migración voluntaria aunque muchos de cllos han migrado también auspiciados por programas de ayuda al refugiado.

Entorno ISSN: 2218-3345

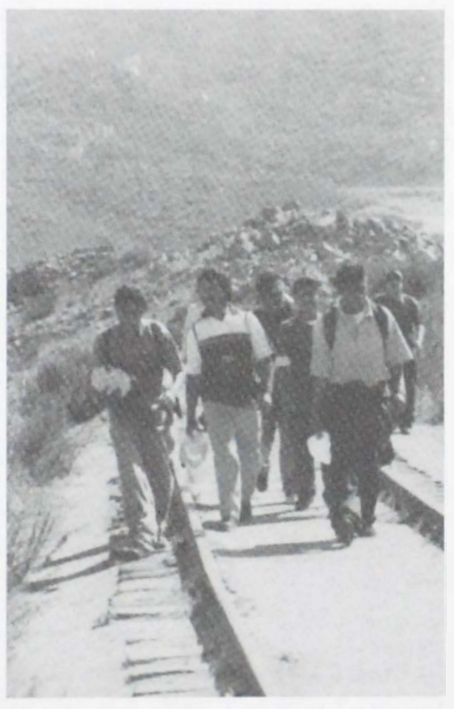

Foto: Gianni Agostinclli/Migruntes No. 3. 2000
¿Dónde tun? l:I principal país de destino de la migración s.lvadorena son los lissados Unidos, donde residen la mayor parte de migrantes, es en California y fundamentalmente en ciudades como l.os Ángeles o San Francisco. L.os investigadores han manilestado la necesidad de investigar la conformación de la idenridad salvadoreña en cada una de las ciudades de los Estados Unidos.

C.anada y Australia constituyen los siguientes paises de destino de la migración salvadoreña. Mfuy por detris se encueneran oeros lugares.

¿Por qué se van? Habitualmente las causas de los movimientos migratorios se analizan bajo la perspectiva de los "factores push and pulf", de empuje y atracción con la traducción castellana. Los lactores push o de empuje son las condiciones en la sociedad de procedencia que morivan la migración mieneras que los lactores pullo de atracción scrían los atractivos que la sociedad de destino tiene para los potenciales migrantes. En cl caso de Eil Salvador los factores pusly yue se han tenido en cuenta han sido la guerra, la alta densidad de población, las exeremadas condiciones de pobreza y otros. Y en cuanto al factor pull fundamental ha sido la necesidad de ciereo ripo de mano de obra en Estados Unidos que cubren los salvadoreños junco con otros lacinos en el pais.

Sin embargo, la ceoria de los factores de empuje y atracción ha sido muy discutida por interpretar de forma mecánica un fenómeno tan complejo como la migración. I.os crícicos de la teoría afirman que la simple enumeración de factores no ofrece una explicación de porqué una persona decide migrar o muchas personas. Al fin $y$ al cabo similares condiciones en otros países no crean fenómenos migratorios. En el caso de los paises centroamericanos cxisten paises con similares condiciones económicas y sin embargo, El Salvador es el que tiene un mayor número de migrantes.

En el fondo la ceoria de los factores empuje y expulsión mantiene implicito la idea de ser humano como homo occonomicus sin exner en cuenta la perspectiva individual y social de las personas migrantes. Mantiene, pues. un enfoque economicista y no integral de las migraciones.

Febrero-Marzo 2002, 항 
Esto no signitica que los factores push and pull quedan invalidados sino que deben formar parte de una perspecriva más global $\mathrm{c}$ integradora, considerando siempre a los Estados dentro del sistema capitalista mundial y dentro del proceso de globalización que sufre el planeta.

El enfoque estructural mantiene que las causas de las migraciones son estructurales a los sistemas socio-económicos nacionales. La perspectiva además no es únicamente económica sino también política, social y cultural. El resultado es una explicación que fundamenta las razones de las migraciones en la misma base social, en este caso, tanto de Estados Unidos como de El Salvador.

Con este enfoque estructuralista, Thomas Winschuh' ha interpretado la migración salvadoreña a Estados Unidos, como un sistema económico excluyente de una importante proporción de la población. Un factor muy importante es la migración campo-ciudad que tuvo lugar en el pais a partir de los años cincuenta que constituye para muchas personas un desarraigo que facilita el salto a Estados Unidos. La minimización de la población campesina salvadoreña que llega del ámbito rural a incorporarse a la ciudad con el considerable cambio cultural. El conflicto bélico jugó el factor de todo desestabilizador de la sociedad. En la migración salvadoreña son fundamentales las redes trasnacionales cada vez más potentes que garantizan la continuación de las migraciones.

Por su cuenta, Estados Unidos, a partir de los años setenta inició una reestructuración económica. El cambio radical en la organización de la producción causada por la microclectrónica modificaron los perfiles de capacitación exigidos. Se crearon empleos en dos ámbitos fundamentalmente. El primero en los puestos que requieren una altísima especialización y en el otro extremo los empleos de rutina. En estos últimos se han incorporado los migrantes indocumentados residentes en Estados Unidos y en su caso lo salvadoreños.

Los empleos de rutina se caracterizan por tener unos salarios bajos; con pésimas condiciones debido a la situación ilegal de los protagonistas; existen pocas o nulas oportunidades de ascenso o de capacitación; poco prestigio social y permanente temor a ser denunciados, detenidos o deportados. En general los estadounidenses blancos no desean ocupar este tipo de puestos y optan por otros mejor pagados $y$ con mayor prestigio social.

Para el autor, el mayor control de la migración "ilegal", que se incrementa en las fronteras, no la elimina sino que la aumenta. $Y$ en todo caso, con este mayor control se están defendiendo los intereses de los empresarios que urilizan mano de obra inmigrante, de bajo costo y carente de protección legal. Existe una complementariedad en los sistemas económicos estadounidense y salvadoreño.

\section{Explicación estructural de las migraciones}

【 a investigación estructural del fenómeno migratorio xplicación integral que arroje luz sobre las causas del problema y el proceso por el cual se lleva a cabo.

Por supuesto, los factores planteados por la tcoria push and pull no son negados en sí mismos. Es decir, la exclusión del mercadolaboral salvadoreño de una proporción elevada de sus habitantes hemos de tenerla en cuenta. O que los emigrantes salvadoreños se van a Estados Unidos, porque allí es fácil conseguir trabajo es evidentemente.

La crítica que se hace, fundamentalmente, es que hay que dar una explicación más compleja que tenga en cuenta el mayor número de factores posibles, para entender mucho mejor un fenómeno que está cambiando, no sólo la sociedad de destino, la estadounidense, sino también la de origen, la salvadoreña.

Winschuh ${ }^{2}$ ha ofrecido una explicación estructural a las migraciones internacionales ocurridas en El Salvador hacia los Estados Unidos de América. Para el autor la explicación radica en la complementariedad de los mercados de trabajo de ambas naciones.

Por una parte, la sobreof erta de trabajo de la economía salvadoreña provocada por la orientación cada vez mayor hacia la agroexportación del café; un proceso de industrialización dependiente de otros centros y el colapso de la economía salvadoreña durante la guerra. Estos factores pusicron en disposición a migrar a una parte importante de la sociedad salvadoreña.

Por parte de los Estados Unidos, el proceso de reestructuración económica que provocó la demanda de puestos de trabajo con mano de obra no especializada y mal remunerada.

Un punto importante para entender la continuación de las migraciones son las redes de solidaridad salvadoreñas. Éstas son un motor de migración en el sentido de que vinculan ambos lugares, facilitando a los potenciales migrantes su decisión y su progresivo asentamiento en las ticras del Norte.

Las redes de solidaridad ponen en comunicación a Estados Unidos y El Salvador. Los protagonistas son las personas migrantes y forman parte de un entramado transnacional. Estos espacios transnacionales rompen las fronteras físicas tradicionales de las naciones y no pertenecen con exclusividad a ninguna de ellas. Son espacios sociales nuevos que configuran puentes de comunicación e intercambio de mercancías, personas, ideas, información, etc.

Febrero-Marzo 2002, Nº 23 
Estas redes de solidaridad se asientan sobre el espacio social transnacionalizado que son nuevos espacios sociales de referencia económica, social, política y cultural.

El estudio de los movimientos migratorios con la distinción de éstos, como temporales y permanentes, se muestra como inoperante una vez aceptado el concepto de espacio transnacional. Muchos migrantes se mueven en un sinfín ir $y$ venir entre las dos naciones, residiendo y trabajando en ambos espacios independientemente de su residencia legal.

Otro elemento fundamental del transnacionalismo, es el modo de vida de los migrantes en los lugares de destino. Los migrantes salvadoreños recrean en las ciudades donde viven las formas de vida salvadoreñas compartiendo muchas veces el espacio con otras nacionalidades latinoamericanas. De este modo muchos productos de consumo, eminentemente salvadoreños, así como otros servicios indicados para clientes centroamericanos son of recidos en los barrios de mayor concentración de habitantes centroamericanos. En estos restaurantes, tiendas y negocios los migrantes satisfacen sus necesidades de consumo de productos que la sociedad estadounidense no of rece por sí sola.

A la vez, los migrantes satisfacen la necesidad cultural de sentirse identificados en su vida cotidiana con la comida rípica, la música y las artesanias de sus propios lugares de origen y en su lengua materna. En estos espacios físicos urbanos moldeados a la medida de sus habitantes salvadoreños y centroamericanos son también espacios de apoyo a grupos culturales y asociaciones deportivas al modo de los salvadoreños y que apoyan de nuevo el proceso de identificación individual y grupal de los migrantes.

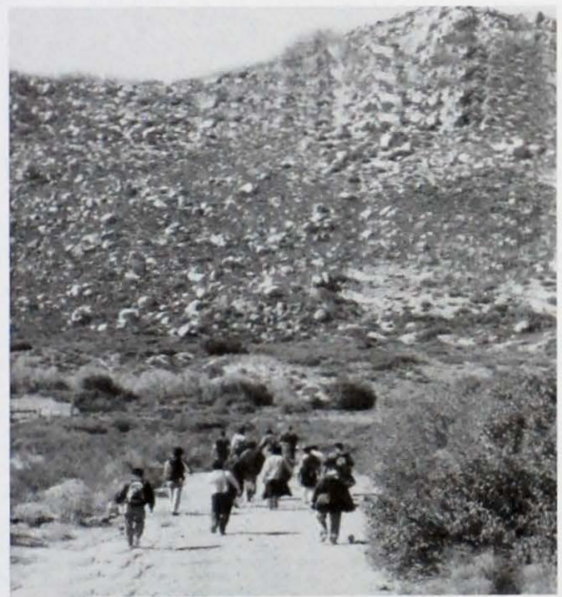

Entorno Cinni isosi ISSN: $2218-3345$
De estos espacios también surgen asociaciones de representación local del lugar específico de origen, se unen y reúnen con el morivo de apoyar y ayudar a su pueblo de discintas formas. Las personas que migran mantienen el contacto con sus familiares $y$ amigos en El Salvador $y$ regresan en momentos importantes de celebración familiar y/o local. De este continuo contacto surgen las relaciones más allá de la mera visita familiar. Esta, ha sido la vía de apoyo entre las asociaciones en Estados Unidos y el pueblo de donde salieron.

Estas asociaciones inciden de distintos modos en la vida local de las poblaciones en El Salvador. Pueden servir de apoyo puntual en la compra o construcción de un objeto o espacio concreto. En los pasados terremotos del 13 de enero $y$ de febrero en El Salvador, estas asociaciones of recieron una ayuda a las poblaciones locales muy interesante como alternativa a las ayudas oficiales tardias.

En otros momentos y circunstancias y como vamos a ver más adelante estas asociaciones pueden convertirse en un factor novedoso de política local.

\section{Cinco dimensiones de análisis de las migraciones}

$\mathrm{D}$ esde hace algunos años se están realizando análisis sobre el tema migratorio alcjándose de la perspectiva meramente económica para ahondar en estudios de carácter socio-cultural. El cambio de enfoque radica en una obligada perspectiva más global y en los cambios culturales que ya son evidentes en la sociedad salvadoreña, a simple vista por todos, y que superan la rápida extensión de restaurantes de comida rápida y la apreciación positiva de todo lo llegado desde el Norte.

Para Mario Lungo ${ }^{3}$, podemos hablar de cinco dimensiones de análisis para abordar de una forma integral el movimiento migratorio salvadoreño con destino en otros paises fuera de la región centroamericana.

La primera dimensión de análisis es la económica. Se incluyen todos los resultados de las investigaciones sobre las remesas enviadas por los salvadoreños en el exterior a sus familias. Desde un punto de vista macro, las remesas representan un punto fundamental para la estabilidad económica de El Salvador. El valúo total de las remesas familiares enviadas al país en el año 2000, fue de mil 759 millones de dólares. Desde esta perspecriva amplia, sin la importancia de las remesas no habría sido posible dar el salto de la dolarización semioficial a la dolarización toral de la economía salvadoreña desde el 1 de enero del año 2001. Las remesas fueron el punto crucial en el periodo de guerra civil en El Salvador para evitar el crack económico. Y en estos momentos suponen también la compensación de la balanza comercial, equilibrando la diferencia entre importaciones $y$ exportaciones. ano

\section{a}

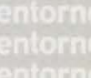

대
ent

$-8$


Algunos autores manifiestan el peligro de tomar las remesas familiares como un punto a largo plazo en la economía salvadoreña. La historia de las migraciones en otros lugares manifiestan cómo los migrantes dejan de enviar ayudas económicas a sus familiares en el largo plazo. Por un lado, porque los lazos con los familiares en el lugar de nacimientos se van acabando o bien porque los familiares mueren o se desplazan a residir con los migrantes. $\mathrm{Y}$ por otro, porque efecrivamente los migrantes conforme pasa el tiempo y van estableciéndose en el lugar de destino envían menos remesas. De hecho, los migrantes que más dinero envían son los recién llegados. Después van enviando dinero de forma esporádica o dejan de enviar. Por lo tanto, valdría tomarlas en cuenta como factor de desarrollo en estos momentos.

Las remesas familiares son la consecuencia económica más visib!e y evidente de las migraciones internacionales en El Salvador. Es el aspecto más estudiado y que mejor conocemos su comportamiento. El Banco Central de Reserva mide los niveles de remesas e interpreta los datos en un sentido macro para la economía del país. También es posible estudiar el impacto de las remesas desde el punto de vista micro. En este sentido las familias salvadoreñas receptoras de remesas han conseguido sobrellevar mejor su propia situación económica familiar.

Muchas anécdotas se han dado a conocer en este sentido. En el caso de San Isidro por ejemplo, investigado por Juan José García ${ }^{4}$, se dan a conocer cambios en el núcleo familiar muy evidentes como un nuevo equipamiento del hogar y otras posesiones como adquisición de automóviles pick-up y de algunas tierras, asi como el mejoramiento sustancial de las casa de los receptores de remesas. Para el autor en San Isidro, el impacto de las migraciones en la recepción de remesas es tal que el monto total de lo producido en la población se ve superado por el total de remesas recibidas. Como consecuencia, las remesas tienen un efecto directo en los niveles de pobreza de la población que las reciben.

Esto en el caso de San Isidro, donde el impacto de las migraciones es fuerte. Sin embargo, debemos de pensar que en otros lugares del pais las consecuencias no son tan evidentes nit tan directas. Para entender esto hemos de pensar que la recepción de remesas no es constante debido principalmente a la situación de los migrantes que las envian. Los salvadoreños en Estados Unidos, la mayoría de las ocasiones trabajan en el subempleo estadounidense, sin las prestaciones de otros trabajadores "legalizados". Por lo tanto, no siempre están en disposición de enviar grandes cantidades de dinero a sus familiares.

En general y sintetizando el impacto de las remesas desde un punto de vista local hemos de afirmar que "éstas son un mecanismo de redistribución del ingreso, de mejoramiento del nivel de vida y de un instrumento de superación de la pobreza"s.

La dimensión territorial: En la dimensión territorial de análisis de las migraciones internacionales podemos observar la importancia de la situación geográfica de los paises y en el interior de éstos en referencia a las fronteras nacionales.

Desde un punto de vista amplio de la región, la situación geográfica de los países centroamericanos, se convierte en lugar de tránsito de los migrantes suramericanos que van por tierra hacia el sucño americano.

Hasta hace unos años los migrantes con destino final en los Estados Unidos, veían en el paso de la frontera de México la mayor dificultad para conseguir pasar de forma indocumentada hacia el pais del norte. Con el endurecimiento del paso de las fronteras y la presión cjercida sobre México los migrantes centroamericanos debian atravesar otro obstáculo: la persecución de los "ilegales" en México con peligro incluso de deportación y por otra parte mezclado con la red de corrupción existente en el país del Norte y que progresivamente han denunciado las organizaciones que tratan de velar por el respeto de los derechos humanos de los migrantes. Estas organizaciones denunciaban el maltrato incluso de las autoridades policíacas mexicanas.

A pesar de la experiencia vivida por la sociedad salvadoreña, y en general centroamericana, ante la presión cjercida por las autoridades migratorias, en estos momentos en El Salvador también se está controlando con mayor esfuerzo el paso de indocumentados por territorio nacional. Sin embargo, otros paises de la zona, quizás con la presión estadounidense, lo están haciendo. De forma que desdehace unos años el mayor obstáculo de una persona que decidia migrar hacia Estados Unidos estaba en la Frontera Norte con México. En la actualidad, los peligros y los obstáculos se han incrementado de forma que el paso por territorio guatemalteco es también un peligro para el vulnerable migrante indocumentado, en un constante peligro latente de verse asaltado, vejado e incluso asesinado en cualquier momento.

Sorprendentemente en un pais de migrantes las autoridades migratorias salvadoreñas se han unido a la presión sobre los indocumentados y están deteniendo a colombianos y ecuatorianos que huyen de las crisis económicas que están viviendo en sus respectivos paises. Colombianos y ecuatorianos pasan por El Salvador de camino hacia Estados Unidos en busca de mejor oportunidades al igual que los salvadoreños.

La justificación of recida por las autoridades migratorias salvadoreñas, ante tales hechos es que éstos sudamericanos 
pretenden pasar por el pais como un trampolin hacia los Estados Unidos, hecho fácilmente comprobable. Pareciera que esta colaboración no firmada bajo ningún convenio entre paises of rece mayores posibilidades a los salvadoreiios en el exterior. A pesar de no existir un acuerdo escrito con el pais del Norte, el director de Migración, Roberto Machón, afirma que las mayores restricciones de paso y control a los sudamericanos garantiza una buena imagen que pudiera, en un determinado momento, convertirse en puntos a favor de la política migratoria hacia los norteamericanos ${ }^{6}$. Para mayor evidencia de esta colaboración, los pasajes de vuelta a sus lugares de origen de ecuatorianos y colombianos son financiados en muchas ocasiones por Estados Unidos. micro, observando los cambios por regiones y ciudades dentro de un país. Quizás un ejemplo sintomático nuevo es el cambio físico y urbanístico de las poblaciones receptoras de remesas del cual hemos hablado en parte. Otro ejemplo fundamental es la importancia distinta que han suf rido los municipios cercanos a las fronteras. Tecún Umán en la frontera entre Guatemala y México, es un ciudad que se ha visto modificada por la cercanía a la frontera Sur mexicana. También es un ejemplo paradigmático del incremento de las dificultades del camino de centroamericanos y sudamericanos en tránsito hacia el sucño americano. Tecún Umán contituye un lugar de descanso, donde retomar fuerzas y prepararse para cruzar la frontera.
Las autoridades migratorias salvadoreñas están ejerciendo un control que incluye no sólo a los indocumentados que atraviesan territorio nacional, sino también ejerce una mayor revisión a la migración que cumple todos los requisitos legales. De esta forma se les negó la entrada, en marzo del 2001 , a ciento diecinueve ecuatorianos que trataban de ingresar al pais por el Acropuerto Internacional de Comalapa?.

Estos hechos nos muestran las implicaciones que tienen las migraciones internacionales desde el punto de vista territorial. La

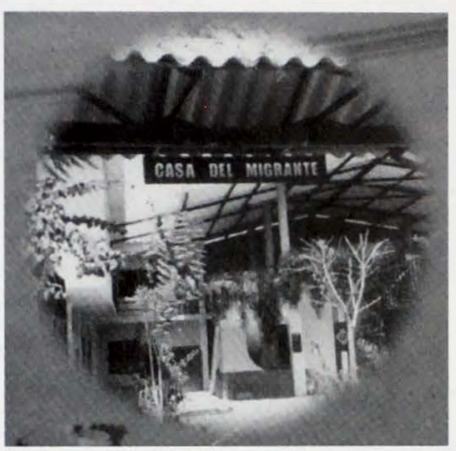

Foro cortesia: Carecen-El Salvado
En este lugar, por cjemplo, inclusola vida coridiana se ha visto modificada por la llegada de estas personas de forma continuada. Debido al tránsito de migrantes indocumentados desde 1994 se construyó un Albergue de atención al migrante que ha servido de apoyo a las personas en tránsito y como observados vigilante del fenómeno. Con la acción vigilante del albergue y personal especializado se han visto reducidos los atentados contra los derechos humanos de los migrantes.

La dimensión social: En esta dimensión de análisis del fenómeno migratorio en El Salvador entran a situación geográfica de El Salvador lo habilita como lugar de tránsito de migrantes sudamericanos, estableciéndose debido a cllo una doble actuación de respuesta al fenómeno migratorio. Por una parte, el gobierno salvadoreño forma parte de las autoridades que se quejan ante los abusos cometidos a salvadoreños en los lugares de destino y tránsito de migrantes. Solicita, entonces, untrato respetuoso con los derechos humanos que tenemos todas las personas aún hayan salido de sus lugares de nacimiento para residir en otros países. Se une además, la llamada para solicitar privilegios para los salvadoreños en el exterior. Pero por otra parte, actúa de forma cada vez más rotunda con los indocumentados que atraviesan territorio nacional. Las detenciones de los sudamericanos se realiza en lugares no aptos al no tener las condiciones adecuadas y sin el presupuesto suficientepara la nueva situación que af ronta. Por lo tanto, no se están respetando los derechos fundamentales de estos. La misma queja se realiza continuamente a favor de los migrantes indocumentados salvadoreños en los países de tránsito".

La dimensión territorial de las migraciones internacionales también la podemos valorar de una forma colación aspectos que hasta hace unos pocos años no han sido tenidos en cuenta en el tema. La observación de las consecuencias de las migraciones a menudo se reduce a la cuantificación de las remesas familiares. Comohemosvisto la profundidad del fenómeno es mucho mayor $y$ afecta a todos los espacios de la sociedad salvadoreña.

Desde la dimensión social se tienen en cuenta los distintos cambios sociales que se están produciendo en el seno de la sociedad salvadoreña. En este sentido se están produciendo fenómenos de desintegración o modificación de roles sociales. Por ejemplo, las mujeres, cuya función tradicional ha sido atender los espacios reproductivos de la vida familiar, pasa a tener un papel totalmente protagónico en caso de que su compañero se marche a los Estados Unidos.

Las mujeres también están migrando, muchas veces solas, con todo lo que ello implica el desarrollo de una mayor independencia al tener que subsistir en una nueva situación. El contacto con una sociedad que respeta mucho más la independencia femenina modifica comportamientos $y$ actitudes de muchas migrantes que intentan trasladar estos 


\section{chisering

comportamientos a su vida salvadoreña. En la sociedad salvadoreña, mucho más conservadora en este sentido, muchas veces es corregida la actuación mucho más libre e independiente de las mujeres migrantes. La mayor libertad de elección en la vida de las mujeres es interpretada muchas veces como un exceso de libertad sexual y por ello mismo condenada.

Las personas de la tercera edad también pueden llegar a adoptar un rol más protagónico en el nivel familiar puesto que en multitud de ocasiones se hacen cargo de los hijos de los migrantes suscituyendo a los padres que están fuera.

En general, las migraciones generan cambios en el núcleo de la familia. La separación física entre los individuos que conforman la familia produce una desintegración de las relaciones familiares tradicionales siendo quizás éste el principal cambio social. Es necesario investigar las nuevas formas familiares que se están creando como consecuencia de las migraciones, sobre todo porque muchos niños están creciendo $\sin$ las figuras paternas presentes.

La dimensión cultural: La dimensión cultural del problema de las migraciones en El Salvador hace referencia a los cambios en las percepciones, valores $y$ aspiraciones como resultado del fenómeno. Se refiere a los cambios experimentados por la sociedad salvadoreña que menos referencias investigativas tiene. De hecho, al igual que con los cambios sociales se observan a nuestro alrededor hechos que tienen implicaciones más profundas en la apreciación sobre la misma realidad salvadoreña.

Los migrantes que van y vuelven, muchas veces en un movimiento pendular, desde EI Salvador hacia los EEUU u otros países son elementos de cambio social y cultural. La residencia por años de estos salvadoreños en otros lugares modifican las apreciaciones y actuaciones sobre la función social de las mujeres o las actitudes frente a la pobreza como ejemplo. Los migrantes son personas más críticas ante el poder establecido, tras unos años de residencia en países donde el desarrollo de la democracia y el respeto a los derechos de los ciudadanos es mayor. Los términos de comparación con otras realidades en el mundo hace que comprendan mucho mejor la propia realidad salvadoreña y los niveles de conformismo disminuyen.

Por otra parte, la imagen de los Estados Unidos, principalmente of recida por los medios de comunicación y expresada directamente por la experiencia de los migrantes, ha modificado la idea que la población tiene sobre su propio país. En este sentido hay una asunción de que los productos estadounidenses son mejores que los salvadoreños que ya se ha constituido en una estrategia comercial para promocionar electrodomésticos, ropa, llantas..
La atracción por lo estadounidense muchas veces se traduce en una copia de acritudes e ideas que se mezcla con las caracteristicas culturales salvadoreñas dando como resultado un híbrido propio.

Los mejores regalos que los migrantes of recen a sus familiares y amigos son productos realizados en el país del Norte. Desde electrodomésticos hasta bebidas, productos de higiene personal y discos compactos llenan las casas salvadoreñas. A veces, los productos están en un contexto de subdesarrollo creando situaciones paradójicas como la anécdota de la lavadora en un cantón de San Isidro sin conexión a la corriente eléctrica?.

La influencia es particularmente especial en el grupo de jóvenes y niños. Éstos se ven impresionados por las imágenes de esplendor y lujo arrojadas desde la relevisión y confirmadas a su vez por las conversaciones de los migrantes. El American Way of Life es apreciado como la mejor situación de status social y por lo ranto la migración hacia los Estados Unidos de América se ve en muchas ocasiones como la única salida posible hacia un futuro mejor.

Un ejemplo concreto de este hecho radica precisamente en los jóvenes de San Isidro que manifiestan la necesidad de migrar para ascender socialmente y como único mecanismo viable para poderlo realizar. La migración al pais del Norte es la vía fácil y segura de ascenso social. Las oportunidades internas en el pueblo y en el país con ese objetivo se aprecian como nulas ${ }^{10}$

El interés en este lugar por la educación formal desciende a niveles bajos cuando la apreciación es que no les va a servir cuando den el verdadero salto hacia los Estados Unidos. La educación formal, más que la preparación para desarrollarse plenamente en su vida productiva posterior, los jóvenes la interpretan como el desarrollo de habilidades que les puedan servir para incorporarse al contexto estadounidense. Por ello, dentro de su enseñanza el inglés es la prioridad"

Desde otra perspectiva siempre dentro de la dimensión cultural surgen otro cambios que son evidentes a ojos de todos. Los jóvenes, especialmente, han adoptado la indumentaria estadounidense en forma de $t$-shirts, pantalones anchos, zapatillas deportivas, pantalones jeans, gorras... Lo cual nos evidencia, en parte, una influencia cultural y a estética y que homogeniza a los jóvenes de distintas partes del mundo. El lenguaje también ha sido modificado con la introducción de palabras y construcciones sintácricas provenientes del spanglish de los barrios latinos de las ciudades estadounidenses. Es habitual el uso de anglicismos y de palabras en inglés para referirse a situaciones u objetivos que tienen su calificativo correspondiente en castellano. Palabras como okcy, full, guachar, cachar, hot dog, sandwich, lunchera, baby shower, shinpinilla, jeans, sweater clutch, freakear. breakear, brazier, chatear.. 
La influencia cultural desde los Estados Unidos, como vemos es más evidente entre el grupo de niños y jóvenes. Asimilan muy fácilmente los modos de vestir, hablar $y$ expresarse que les llegan a través de diferentes canales.

Siguiendo con el tema de los jóvenes cabe señalar aquí una acusación que habitualmente aparece a colación del comportamiento de estos con respecto al trabajo. A menudo existe la apreciación de que los jóvenes receptores de remesas dejan de trabajar en labores productivas, se les acusa de holgazanes por dedicarse a escuchar música en inglés en los lugares de esparcimiento. Se percibe a los jóvenes salvadoreños como excesivamente impresionados e influenciados por la imagen más positiva del sueño americano. Desde esta tradición salvadoreña se define a los habitantes del país como buenos trabajadores, por lo tanto, estos jóvenes con su comportamiento están traicionando uno de los elementos de la salvadoreñidad.

A los antropólogos les preocupa esta observación al respecto de los jóvenes. Un estudio realizado en Santa Elena, revela la falsedad de las relaciones directas enere juventud salvadoreña, la migración internacional y la improductividad laboral. En el fondo de esta asociación se encuentra la discusión sobre la urilización productiva o no de las remesas recibidas por las familias salvadoreñas. La apreciación es que las remesas se malgastan en productos suntuarios, lo cual sería un cjemplo de la aculturación salvadoreña al modo de vida consumista estadounidense. Pero los investigadores manifiestan que es un hecho la improductividad del agro salvadoreño y que en este hecho tienen que ver muchos factores estructurales a la economia salvadoreña $y$ sus relaciones comerciales internacionales. Sin embargo, la apreciación de que los jóvenes se han apartado del gusto por cl trabajo duro, traicionando de estc modo la salvadoreñidad está relacionado a cambios en las actitudes frente al trabajo agrícola. Los jóvenes ya no ven en el trabajo agrícola lo mismo que otras generaciones anteriores y prefieren incorporarse a otro tipo de relaciones laborales. Este cambio cultural debe explicarse como una conjunción de factores y no únicamente a partir del efecto de las migraciones internacionales.

La dimensión politica: La dimensión politica de las migraciones internacionales hacen referencia a múltiples aspectos surgidos de la nueva sociedad hibrida que se está conformando por la influencia estadounidense.

Desde un punto de vista amplio. el primer debate que suscitan las migraciones internacionales en el ámbito político es el derecho a voto de los salvadoreños en el exterior. Existe una estimación de un 20 o un 25 por ciento de los salvadoreños residiendo fuera del pais $y$ todos ellos tienen o tendrán derecho a elegir a sus 
representantes políticos al cumplir la mayoría de edad establecida. Hasta el momento no existen los mecanismos para que los salvadoreños y salvadoreñas residentes fuera de las fronteras del país puedan ejercer su derecho al voto desde sus lugares de residencia sin tener que desplazarse el día de las elecciones a territorio nacional. En principio la carencia de estos mecanismos efectivos implica la negación de este derecho político a los migrantes. En España, resuclven el problema activando mecanismos de voto por correo. garantizando a si el derecho a la elección de los representantes, aunque las personas se encuentren fisera de las fronteras españolas.

En caso de que finalmente se logren concretar las formas para que los migrantes de origen salvadoreño voten, se van a ver ampliados los espacios políticos transnacionales entre los Estados Unidosy El Salvador.

Ya hemos hablado del

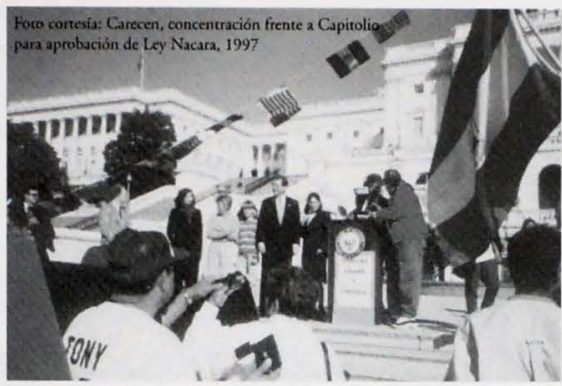

obtener ingresos del transporte de remesas, cartas, regalos, chismes, etc. Elementos de unión entre los dos países, son lazos de carácter económico, social y afectivo ${ }^{12}$.

La fuerza de estos nuevos grupos sociales desplaza a las élites tradicionales del lugar. En San Isidro, por ejemplo, se ha observado la aparición de nuevas élites sociales como capas medias vinculadas a las migraciones, desplazando a las élites tradicionales vinculadas a la posesión de tierras. concepto de transnacionalismo. Sugiere la ruptura de los conceptos tradicionales de nación vinculados a las fronteras establecidas como propias y que separan los espacios entre naciones. Dado el peso cuantitativo de los salvadoreños viviendo en el exterior, los partidos politicos verian como primordial hacer campaña polícica en Los Ángeles, Washington, San Francisco, Virginia..

En general, las migraciones internacionales y los migrantes suscitan un problema para los derechos políticos de las personas. Los migrantes no pierden su derecho a votar en sus paises de origen y otros derechos politicos. Sin embargo, residen muchos de ellos de forma permanente en otro lugar distinto, sin posibilidades de decisión política hasta que se nacionalizan. En Europa, por ejemplo, se están discuriendo modalidades políticas para que los migrantes comunitarios puedan decidir y por lo tanto actuar en la política local del lugar de residencia habitual. Se trata de nuevas definiciones politicas que se crean como consecuencia de fenómenos migratorios.

Desde el punto de vista de la política local en algunas localidades con fuerte migración a los Estados Unidos, se ha documentado la aparición de nuevos grupos sociales en el ámbito local.

Los ericomenderos y encomenderas, migrantes pendulares, son las personas que sirven de puente entre el lugar de nacimiento de los migrantes y su zona de residencia. Viajan constantemente de un lugar a otro con el fin de
Otro clemento político surgido a partir de los migrantes son las asociaciones de salvadoreños en el extranjero, en especial, en los Estados Unidos de América. Son básicamente grupos de personas asociadas en principio por un origen común de una comunidad específica. Son una consecuencia de las redes de migrantes, las cuales han facilitado el encuentro en las ciudades de destino de habitantes de un mismo pueblo. Comienza con la migración de un miembro de la comunidad que se convierte en motor para la migración de sus familiares y amigos. Estos individuos ayudan a otros en el viaje y la incorporación a la nueva sociedad. El resultado por una parte es un impacto tremendo en todos los sentidos en los lugares de una migración fuerte, habiendo poblaciones con distinto impacto del fenómeno incluso en la misma región.

Otro resultado de este mecanismo es la configuración de comunidades de personas del mismo pueblo en los lugares de destino final. De estos grupos aparece un elemento muy importante: las asociaciones de salvadoreños en el exterior. Estas asociaciones agrupan a personas de un mismo pueblo y pueden servir de ayuda mutua en el área deportiva, o como promotores de eventos culturales. Tienen una primera actuación en la sociedad de destino sirviendo muchas veces para la articulación de la nueva comunidad, defendiendo sus derechos e intentando de igual manera abrirse camino.

Estas asociaciones tienen un referente local muy concreto, un especial interés y compromiso, que genera un papel porencial para el desarrollo de los distintos pueblos salvadoreños. Las asociaciones son un elemento que interfiere en la politica local. Por su capacidad de financiación de proyectos, son capaces de apoyar la celebración de las fiestas patronales o de construir una cancha de fútbol o de enviar ayuda de emergencia en los recientes terremotos que afectaron a El Salvador. Estas actuaciones se hacen con o sin la colaboración de los gobiernos. El potencial de estas 
asociaciones modifica la apreciación de la política local y central, por parte de las comunidades de origen.

\section{El lado menos conocido de las migraciones:} los desaparecidos en las fronteras.

$\mathrm{O}$ tro gran aspecto de las migraciones internacionales en El Salvador son las desapariciones de personas migrantes en el camino "ilegal" hacia el "American Dream". A muchas personas, les ocurren incidentes de diverso tipo. miles mueren a causa de los accidentes en los pasos peligrosos de las fronteras o tienen el mismo final fatal al encontrarse con las bandas de asaltantes que pululan en busca de indocumentados vulnerables. Ambos grupos de personas viajaban sin la autorización y visados pertinentes por lo que son encontrados habitualmente muertos sin documentación que los identifique, siendo enterrados en los cementerios de las localidades bajo el rótulo de "desconocido".

Carecen Internacional ha logrado identificar a algunos salvadoreños a pesar de la dificultad existente. En un boletín del año 2000 hablan de un total de 9 casos de desaparecidos localizados muertos en Guatemala y México. El proceso es complejo puesto que viajan sin identificación pero comienza cuando los familiares aquí en El Salvador o en el lugar de destino no reciben noticias de la persona. Carecen es un apoyo porque tiene conexiones con otras ONGs preocupadas por el problema de las violaciones de derechos humanos de los migrantes. Gracias a estos contactos se han podido repatriarvarios cadáveres de salvadoreños, con esto Carecen aporta un tratamiento humano de las migraciones y de sus consecuencias menos conocidas. Estos acontecimientos se alejan mucho de la imagen positiva de las migraciones internacionales.

El Programa de Atención a los Inmigrantes Salvadoreños (PAIS) ;Bienvenido a casa! Es un proyecto amplio que intenta abarcar toda la problemática de la migración salvadoreña. Instituciones gubernamentales, ONGs, Iglesias, el sector privado y centros académicos forman parte de la comisión técnica. Siendo el Comité Director el viccministro del Interior, el viceministro de Relaciones Exteriores y la representación regional de la ()rganización Internacional de las Migraciones (()IM). La política del I'rograma Bienvenido a Casa es la gestión y la coordinación. Ellos no son cjecutores directos de los programas.

El Programa Bienvenido a Casa surge en 1999, como resultado de la declaración de Pucbla, encuentro donde Estados Unidos y los países que presentan un alto nivel de migración tomaron decisiones cruciales en materia migratoria.

El Programa Bienvenido a casa, está cstructurado de la siguiente forma:

- Reccpción: REDES-Concertación

- Alberguc: Cáritas

- Asistencia Legal: FESPAD

- Atención médica: médico privado

- Formación Técnica/Orientación Laboral: Ciudadela D. Bosco; CETEXSAL, ÁGAPE Sonsonate, Fe y Alegría.

- Acreditación de estudios: Ministerio de Educación

El Programa Bienvenido a Casa, recibe desde febrero del 1999 a los deportados que llegan al país desde Estados Unidos. Catholic Relief Service (CRS) es la ONGs encargada de ejecutar el proyecto desde la arribada de las personas al acropuerto, realizando labores de emergencia propias del momento.

La recepción por parte de CRS se realiza dentro de un clima que pretende la disminución del impacto subjetivo y emocional de las personas que retornan involuntariamente a suelo salvadoreño.

Por parte del Programa también existe la intención de conocer más el fenómeno de las deportaciones y para ello realizan una encuesta a cada uno de los deportados, recogen datos de carácter sociocultural de la situación de cada uno de los recién llegados. Estos datos cuantitativos ya conforman una sólida base de datos que permite saber un

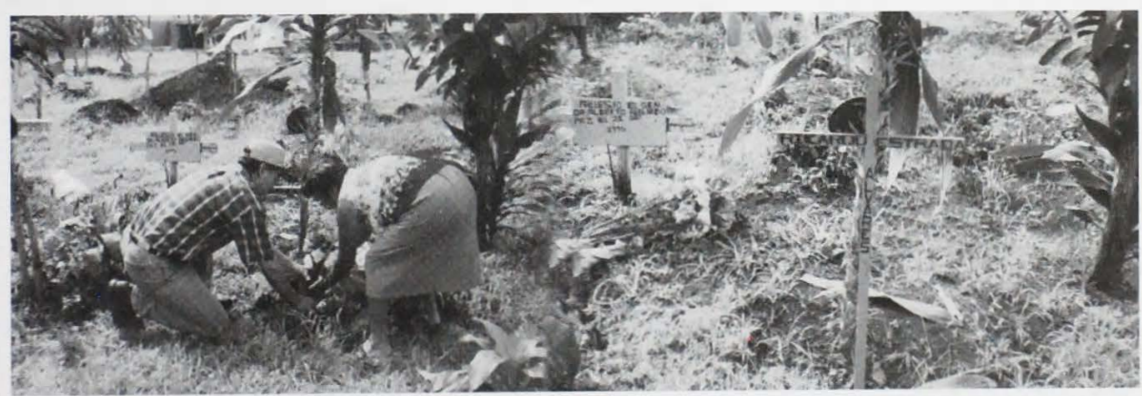


poco mis sobre la vida de los deportados y las condiciones en las que regresan a su país de origen.

Los responsables del programa se preocupan por of recer apoyo a personas, intentan que no sea únicamente una gestión en la que se les entrevista para obtener datos estadísticos o de un intercambio entre instituciones migratorias sino una cálida bienvenida. Para ello, inciden en el tono cordial de las palabras de recibimiento, con la utilización de vocabularios y expresiones propias del dialecto salvadoreño y en la que cobra una especial significación las pupusas que son of recidas por el programa mientras esperan a ser entrevistados.

La entrevista la realizan los encuestadores que acuden a los vuelos charter. Ellos son personal especializado en Ciencias Sociales y por lo tanto tienen una comprensión profunda del fenómeno migratorio en El Salvador, además de haber sido entrenados y capacitados para interactuar con los muchachos recién llegados. En ese sentido para los responsables en el aeropuerto es importante reflexionar con cada uno de los encuestadores para evitar la mecanización de las encuesta de forma que no se olvide la idea central del programa.

La encuesta representa el primer intercambio individual con El Salvador de los muchachos. Existe un doble objetivo en la cncuesta. El primero es obtener información de carácter socioeconómico. El segundo disminuir, en la medida de lo posible, la sensación de frustración que implica la deportación.

El recibimiento por parte de CRS a los deportados se complementa con otro tipo de ayuda esencial en los primeros momentos de arribo al país. Un boletín informativo sobre las caracteristicas básicas de El Salvador, que incluye direcciones y teléfonos así como recomendaciones para la búsqueda de empleo, estudios, lugares de esparcimiento y cómo obtener documentos personales básicos. Incluye información también del agravamiento de la condena por regresar a los Estados Unidos tras haber sido deportado a El Salvador.

El apoyo se amplía en brindar un lugar donde dormir por un riempo máximo de tres días, con el apoyo de Cáritas y el Albergue El Peregrino. También incluye la posibilidad del transporte del aeropuerto de Comalapa hasta San Salvador o las principales terminales de buses.

Luis Perdomo, director del programa por parte de CRS, confirmó que el trato se hace lo más humanamente posible. De forma que se toman en cuenta los casos excepcionales y particulares de las personas que retornan, se arienden las necesidades de forma personal. De forma que si alguno de ellos necesita estar más tiempo en el albergue se le permite. $\mathrm{O}$ si tiene alteradas sus condiciones mentales se le procura atención hasta conseguir localizar a los familiares más cercanos.

El recorno de los deportados no es fácil en los primeros momentos. En este momento crucial de arribada al país las emociones inundan a las personas. El programa en el aeropuerto ha ido evolucionando hasta conseguir ser lo más humano posible con los recién llegados. Con fórmulas sencillas pero eficientes de autoevaluación han mejorado el proceso de bienvenida. Sin embargo, el problema grave es la falta de oportunidades para los recién llegados. En este sentido CRS ha decidido profundizar en la formación de los deportados. Lo cual incluye posibilidades de financiación para microempresas tras la finalización de los cursos. Al proyecto completo que todavía no se ha puesto en marcha en su totalidad se llama "Formación y Orientación Laboral".

Un éxico más del programa Bienvenido a Casa es que algunas de las personas deportadas que regresan al país y que padecen alguna enfermedad grave como tuberculosis y SIDA, son atendidas por el personal de la unidad de salud del aeropuerto, se les realiza un pequeño chequeo médico con el fin de que el tratamiento iniciado durante su estadía en la prisión de Estados Unidos no sea interrumpido una vez se encuentren en el suelo salvadoreño.

Los deportados son conducidos en un vuelo charter en aviones comerciales o fletados especificamente para la deportación de extranjeros en Estados Unidos. En estos aviones ex professo, se incluyen en ocasiones personas de distintas procedencias realizando distintas escalas en el istmo centroamericano. 
Antes de abordar este avión cada uno de los emigrantes es encaninado desde el estado en donde se encontraba encarcelado. A menudo, el intervalo desde el comienzo del viaje hasta la llegada al aeropuerto de Comalapa se lleva entre dos o tres dias, periodo en que los deportados no tienen acceso a bañarse y a ropa limpia. Esto es una violación a la dignidad de todas esas personas de parte de las autoridades estadounidenses.

Otro aspecto primordial que influye psicológicamente son las esposas y grilletes con las que son inmovilizados durante todo el viaje dentro del avión, gracias a la intervención del Programa Bienvenido a Casa, al aterrizar en territorio salvadoreño los deportados son liberados de los respectivos metales.

El Programa también of rece a los deportados llamadas gratis a sus familiares o amigos en todo el país. $Y$ en estos primeros momentos los deportados avisan a sus familiares de que han recornado. A muchos de ellos los recogen en el aeropuerto pero el programa of rece un autobús que los transporta de forma gratuita a San Salvador, a cada una de las terminales donde pueden tomar autobuses hasta sus puntos de destino final. El autobús espera a que todos hayan terminado todo el proceso y entonces parte hacia la capital. El programa ofrece dinero en metálico para que los

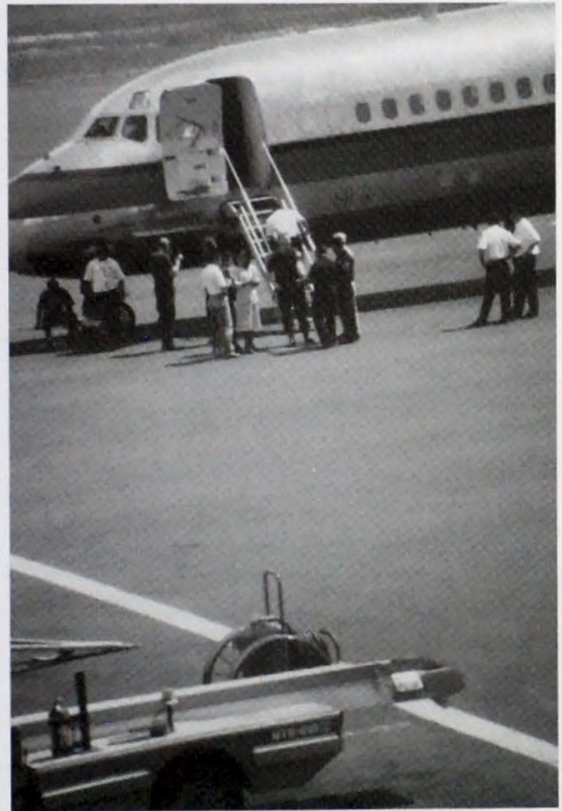

Éntortino Ruball ISSN: $2218-3345$ muchachos paguen todos los billetes de autobús que necesitan ya que muchos de ellos no cuentan con dinero. Un convenio entre Bienvenido a Casa y el Banco Cuscatlán permite cambiar cheques en colones o dólares en el mismo aeropuerto sin necesidad de enseñar dos documentos personales ya que muchos de ellos son indocumentados. $\mathrm{Y}$ para finalizar las medidas de atención de urgencia se les of rece un lugar donde dormir y descansar en caso de que ya no puedan llegar a tiempo a sus lugares de destino o que no tengan un lugar donde llegar. El albergue lo pueden utilizar hasta tres días.

Las preguntas que deben contestar los muchachos están relacionadas con su nacimiento y situación en El Salvador antes de partir a los Estados Unidos; la situación en este pais del Norte, su ocupación y salario. Se preguntan también las expectativas con respecto a El Salvador y su lugar de destino en el pars para poder ser localizados.

Con todo ello el programa Bienvenido a casa posee unos datos estadísticos de más de 6 mil deportados llegados al país. Con estos datos se han elaborado perfiles y tendencias sobre el fenómeno y que tomaremos más adelante.

Tras la encuesta realizada en la sala que el programa tiene en el aeropuerto, los muchachos son conducidos por parte de miembros de la Policía Nacional Civil (PNC) a las instancias migratorias donde se les da también su identificación con la que pueden posteriormente obtener sus documentos en las distintas alcaldias del país.

Antes de salir físicamente del aeropuerto, la PNC realiza una entrevista a cada uno de los muchachos de forma que exista un control mayor por parte de la policia. El personal responsable del programa de bienvenida ha intentado por distintos medios eliminar esta entrevista. Aducen varias razones. La principal y fundamental es que las personas que son deportadas a El Salvador son libres una vě se encuentran en territorio nacional sin importar los delitos cometidos en los paises que los retornaron. De forma que una vez se ha realizado el intercambio entre las instituciones migratorias estadounidense y salvadoreña ellos entran al pais como personas libres. La PNC realiza este control por mandato del Ministerio del interior en un intento de controlar las bandas delincuenciales en el país quizás sin mucho acierto en este caso. Pero existe otro motivo importante por el cual el programa critica esta entrevista. Los muchachos se marchan del aeropuerto con la idea de que han sido "fichados" por la policía. Todo el empeño por parte del programa de que sea una recepción cordial y amistosa se pone en peligro cuando las autoridades intervienen.

El proceso de recepción termina cuando cada uno de ellos recoge "sus pertenencias" en los espacios habituados para ello en el aeropuerto. El equipaje de la mayoría de ellos 
consiste en una caja de cartón con un par de zapatos, un walkman, algún tipo de documentación, algo de ropa, algún libro, la mayoría de las veces Biblias que las iglesias evangélicas regalan cuando visitan a los presos. En algunas ocasiones estas pertenencias van en una simple bolsa de plástico transparente. Otros viajan con maletas pero son la minoría. $\mathrm{Al}$ parecer una vez se ha dictado sentencia de deportación no saben con fecha segura el momento del viaje. Por lo tanto ni siquiera sus familiares o amigos en Estados Unidos pueden apoyarlos comprándoles cosas para su estancia inmediata en el país. El traslado de un estado a otro sin que ellos pueden comprobar que sus pertenencias están completas facilita que éstas sean recibidas en el aeropuerto de Comalapa abiertas y en algunos casos incompletas.

\section{El fenómeno de las deportaciones: una interpretación}

Ta frontera México-Estados Unidos es el lugar

Ludicional de paso de indocumentados hacia el último pais. En esta extensa frontera se han ido intensificando los controles para la detección de los migrantes sin papeles.

Lejos de ahuyentar el flujo de migrantes lo que ha ocurrido es la variación de las rutas por otras menos seguras y más peligrosas. Por lo cual se podría afirmar que el blindaje de la frontera México-Estados Unidos lo que ha causado son más muertes innecesarias.
Los coyotes intentan atravesar por otros caminos peligrosos comolas zonas desérticas donde no hay agua y las temperaturas son elevadas. Las dificultades de atravesar las fronteras se han trasladado cada vę más al Sur.

La Frontera Sur de México nos da idea del tráfico de indocumentados de origen centroamericano. En la Frontera Norte también es un indicador, menos fiable por el trasiego de los mexicanos fundamentalmente y además porque los centroamericanos se manifiestan muchas veces como mexicanos ante las autoridades migratorias estadounidenses, para evitar ser deportados a su propio pais de origen alargando de nuevo la distancia hasta su sueño americano's.

La Frontera Sur en este sentido, repetimos, es el indicador de paso de los migrantes centroamericanos y los puntos de referencia obligada son Tecún Umán en Guatemala en el camino hacia el Norte.

Tecum Umán ha cambiado en muchos aspectos debido al tránsito migratorio. Alli, la Casa del Migante que desde 1994 se encuentra en el lugar ejerce de apoyo a los indocumentados. También realiza labores de control a los abusos de poder por parte de distintas autoridades ante los vulnerables migrantes indocumentados.

Ser indocumentado, ilegal, implica haber transgredido las normas del país de residencia. Como hemos visto, una situación individual de un migrante en particular tiene

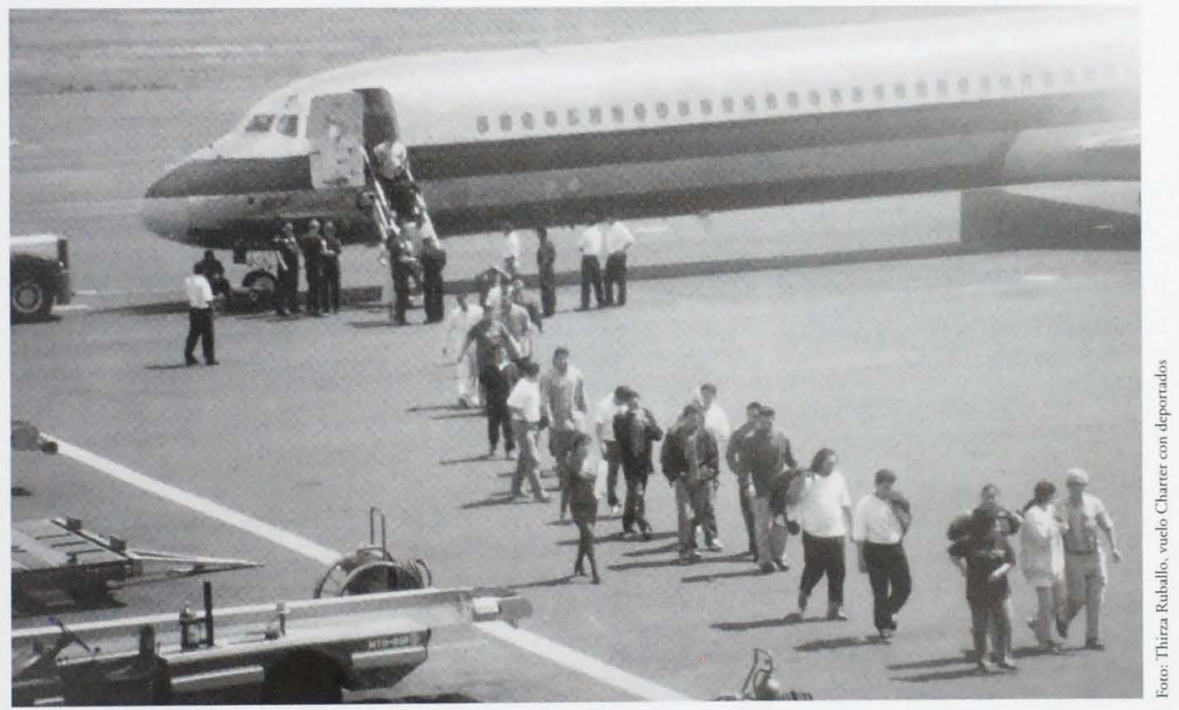


explicaciones muy prof undos de carácter estructural y que relacionan a los dos países, el de origen y el de residencia. La decisión, por lo tanto de estos individuos como indocumentados tiene que ver incluso, con la situación geográfica en la que nació.

En el indocumentado apresado y "removido", en la nueva terminología eufemística estadounidense, queda sinterizada la situación mundial económica y social al mismo tiempo que la división desigual entre un mundo desarrollado y otro subdesarrollado. La penalización que sufren los individuos y grupos de migrantes indocumentados induce a la expulsión de los no queridos, de los no nacidos en los límites que marcan en este mundo la vida del acomodolujoso y la satisfacción material. Es la suerte la que nos marca al nacer en uno u otro lado del mundo.

Para muchas personas la lucha por la supervivencia implica una peregrinación hacia "la tierra de leche y miel" que para los salvadoreños se llama la mayor parte de las veces Estados Unidos.

Las fronteras que marcan los límites físicos entre las dos partes de este mundo se están reforzando en la mayor parte de los casos y blindando en las zonas lindantes con las zonas permeables al flujo de personas indocumentadas. Todo esto en momentos álgidos del pensamiento neoliberal con una libertad absoluta de tráfico de mercancías. Y cuando se están firmando en nuestra región Tratados de Libre Comercio que van a flexibilizar los costos del comercio en la región. Paradojas de finales del siglo XX y principios del siglo XXJ.

Carecen Internacional rotula sus encuentros con una frase escalofriante: "Nada Puede Detener el Sueño de los Migrantes". Y al parecer está en lo cierto. En los objetivos de esta organización surgida a principios de la década de los noventa está el de trabajar para el respeto de los derechos humanos y jurídicos de los trabajadores migrantes indocumentados ${ }^{14}$.

Como institución Carecen también realiza labores de sensibilización para mostrar los riegos en la migración indocumentada. Su experiencia viene marcada por el hecho de que a pesar de los riesgos cada vez mayores siempre hay personas dispuestas a enfrentar el camino hacia su propio sueño. De esta manera queda reflejada en esa frase - lema de las reuniones organizadas por Carecen.

Los especialistas mantienen que a pesar del blindaje de las fronteras y la creciente dificultad en atravesarlas, los migrantes no abandonan la idea de viajar. La dificultad y los peligros cada vez mayores significan en muchos casos la muerte de las personas indocumentadas en las zonas desérticas de la frontera entre Estados Unidos y México, en ríos con corrientes peligrosas o asaltados por bandas de delincuentes. Pero ellos siguen intentándolo.
Finalmente, el incremento de las dificultades y las barreras en las fronteras tiene al menos dos consecuencias directas. Por una parte, el número de muertos y desaparecidos aumenta al incrementarse los riesgos fisicos, y por otra, la ayuda con guías, "polleros" o "coyotes" se hace prácticamente necesaria y por lo tanto se encarece el viaje. Estas son pues, las verdaderas consecuencias de un estricto control migratorio.

De nuevo el problema que tiene raices estructurales y de relaciones internacionales se centro, y persigue en los individuos aislados tremendamente vulnerables. $\mathrm{Y}$ sin embargo, no se persigue seriamente a los empresarios estadounidenses que utilizan mano de obra extranjera, sin prestaciones, con sueldos bajos y sin las condiciones de trabajo ni de vida adecuadas. De forma que el problema de la ilegalidadredunda en los migrantes y no en todo el sistema económico que se ve beneficiado por la migración indocumentada.

El incremento de los controles y por lo tanto de la peligrosidad en las fronteras de camino hacia el Norte también incide psicológicamente en losmigrantes, garantiza el síndrome de clandestinidad. Éstos han de mantenerse en el submundo de la "ilegalidad" para poder subsistir.

El síndrome de clandestinidad comienza desde el mismo momento en que las personas deciden migrar. El carácter de clandestino es asumido de tal manera, que no denuncian muchos veces los atropellos en sus derechos humanos por el mismo motivo de suponerse en un submundo donde no rigen las leyes de justicia escritas en el otro.

Aquí radica la caracterización de las migraciones como una peregrinación. La llegada a Estados Unidos conlleva el éxito vital, representando el lugar por el cual han sufrido tanto en el camino. Se mantienen clandestinos o semiclandestinos en los primeros momentos y progresivamente pueden ir adquiriendo distintos status migratorios hasta incluso la nacionalización. En estos primeros años envían dinero a su familia en El Salvador.

Muchos indocumentados son apresado por carecer de los trámites administrativos que les permitan residir en el país de destino. Son retenidos en cárceles y tratados como delincuentes comunes. La expresión máxima del trato como delincuentes está en mantenerlos esposados de pies y manos en el viaje en avión hasta El Salvador.

Para los deportados que son indocumentados supone un verdadero shock el trato como delincuentes peligrosos inmovilizados con esposas y teniendo que moverse con dificultad y torpeza. El miedo que sentían a ser apresados por El Servicio de Inmigración y Naturalización se hizo realidad y el sueño americano se trunca de repente. 
En el caso de los salvadoreños deportados por motivos de indocumentación o leves son llevados a las cárceles del condado, donde el personal policíaco es af roamericano, latino o anglos de quienes reciben una actitud hostíl y en ocasiones son agredidos. Reciben una poco correcta atención puesto que las cárceles son pequeñas. De las cárceles del condado son trasladados a los corralones o cárceles de migración donde no tienen acceso a visitas y con el objetivo de ser deportados en cualquier momento ${ }^{\text {is }}$

Algunos de los indocumentados deportados son recién llegados, la mayoría llevaban algunos años y por lo tanto habian hecho toda una vida en su nueva ciudad gringa. Amigos, familia, pertenencias materiales... todo se queda allí. La deportación es la ruptura brusca con la vida maravillosa de su capítulo propio del sueño americano. La separación de todo ello es involuntaria, rápida, inmediata... no vale el arrepentimiento, no hay salida, vuelven al país del que salieron y los invade la desesperanza.

Significa la separación tras haber llegado a la "tierra prometida" o "la tierra de leche y miel" a la cual emigraron. Una especie de destierro absoluto sin vuelta atrás que se manifiesta con una depresión psicológica, pasividad y derrotismo. Las primeras impresiones que tienen de su nueva situación no son muy agradables puesto que el camino de regreso es un "castigo" por haber transgredido las normas. El castigo implica no poder regresar a Estados Unidos puesto que si son nuevamente detenidos se les pasa por parte del Servicio de Inmigración y Naturalización (INS) los pasa a la cárcel con una condena de 5 años por ser reincidentes ${ }^{16}$.

En los casos en que el retornado era un emisor de remesas, la deportación tiene consecuencias directas para el sostenimiento de la economía familiar. Con la deportación incluso los objectivos vitales de la familia se ven truncados. Es decir, muchos migrantes tienen en proyecto la migración progresiva de coda la familia en base a la reagrupación familiar, de forma que uno migra y va facilitandola migración del resto de la familia. En primer lugar se observa la migración del padre y luego de la madre hasta que finalmente los hijos viajan a encontrarse con los padres. El proceso puede ser largo pero el objetivo es grupal y beneficia a todos los miembros de la familia.

Con la deportación todo este proceso se ve frustado, y por consiguiente el habitual suplemento basado en las remesas familiares enviadas por ese miembro de la unidad familiar. En los casos en que el migrante indocumentado se marchó con algún préstamo o con el resultante de la venta de algún bien familiar, la situación económica se habrá empeorado mucho más que antes de marcharse puesto que se habia depositado parte del futuro de prosperidad en ese migrante y tras la deportación se quedan sin nada.
En estas circunstancias especificas los deportados se encuentran ante una trampa de la que será difícil salir de nuevo porque efectivamente a su llegada de nuevo a El Salvador se encuentran con las mismas dificultades para incorporarse a la vida productiva. De hecho, si uno de los factores para explicar el fenómeno migratorio es la exclusión económica y la poca capacidad de integración al sistema laboral, al regreso, estas personas se encuentran con una situación similar aunque con un estigma social muy fuerte en la persona deportada. Los encargados del Programa Bienvenido a Casa comentan que hay muchachos deportados que se niegan a salir de sus casas por temor a las burlas y estigmas sociales ante el fenómeno de la deportación. En especial con este grupo de deportados, que son retornados por cuestiones de indocumentación, cae sobre ellos la reprimenda social ante la falta de éxito en su aventura del sueño americano. Efectivamente, la imagen de éxito que predomina en la calificación de las migraciones se contrapone a la situación de fracaso que viven los deportados.

La dificultad de la llegada se ve acolchonada en los primeros momentos por los cuidados de los miembros del programa de recepción en el aeropuerto. Todos coinciden en aceptar que el verdadero problema surge cuando salen de las instancias del aeropuerto para enf rentarse a sus familiares y amigos. La identificación social que se realiza entre deportados y delincuentes pesa en exceso en las personas que se dirigen a sus casas a enfrentarse de nuevo con la pobreza que dejaron. La labor durante estos años de los miembros del programa y el aumento total del número de deportados quizás ha hecho disminuir la presión social ejercida sobre ellos pero en absoluto la ha eliminado. Por ello, van a sentir el temor y la desconfianza incluso de sus allegados ante la noticia de que regresó al país deportado.

Los deportados son conscientes de la situación nueva a la que se van a enfrentar, no en vano, en el mismo aeropuerto la PNC los entrevista como si fueran delincuentes a pesar de no tener problemas con la justicia salvadoreña, pues son completamente libres una vez llegan a territorio nacional.

Hay un grupo de deportados que llevaban muchos años en los Estados Unidos, y que por lo tanto tenían toda una vida allí. La mayoría de éstos han comerido delitos o faltas leves. A menudo se trata de casos de violencia familiar o de agresión física, delitos que efectivamente son sancionables en El Salvador pero que no pesan tan fuerte como en el país del Norte, donde sí tienen muy en cuenta estos hechos delictivos y son motivos de deportación. La deportación se realiza aunque los autores tengan todos sus permisos de residencia en regla.

La sensación que tienen los deportados y sus familiares es que las autoridades les han tratado con un exceso de mano dura, calificando una pequeña falta como causa de 


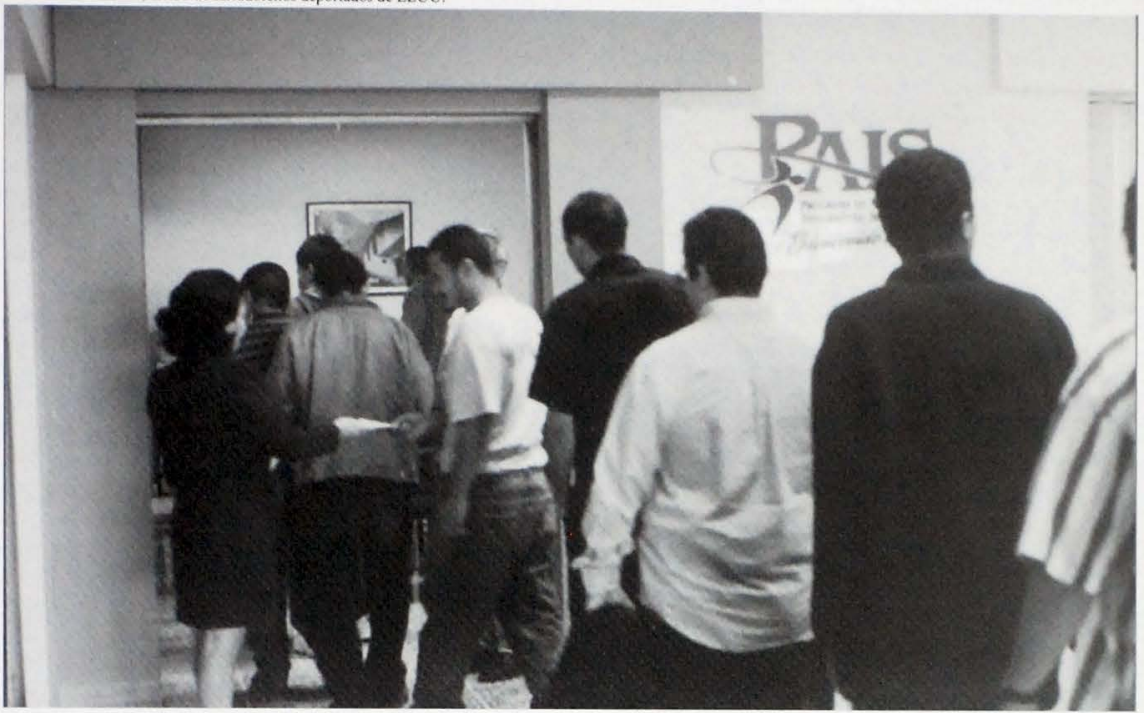

deportación. Muchos además califican el hecho como de un ef ecto de la discriminación racial ante los latinos en los Estados Unidos. A pesar de haber obienido muchos de ellos la residencia definitiva incluso, siguen siendo extranjeros, latinos. En lo que califican como un sistema social de conductas intachables en el que cualquier crror se paga muy caro. Pero la consecuencia de una pequeña falta o de la mala suerte provoca un efecto dominó que acaba con la vida completa de la persona deportada, puesto que de ahi se pasa a la cárcel y de ahí al poco tiempo a El Salvador en un avión esposado de pies y manos al lado de posibles delincuentes en el más extenso sentido de la palabra.

En estos casos el drama se vive de forma intensa puesto que se encuentra sólo en EI Salvador tras una vida de años y años en un país distinto. Han sufrido un proceso de aculturación evidente en la forma de hablar, con un acento mezclado con ritmos propios del inglés, con expresión y movimientos del cuerpo propios de otra sociedad. Trae consigo además otros cambios quizás no tan evidentes a simple vista. Son distintas actitudes ante la vida y ante la misma realidad salvadoreña de la que salió mucho tiempo antes. Puede que no haya perdido el contacto totalmente con sus últimos familiares en el Pulgarcito de América, pero no pensó regresar precisamente porque continúan las carencias de las que huyó y la falta de oportunidades.

Son salvadoreños pero cuestionan incluso el concepto de la existencia de una sola identidad salvadoreña vinculada al territorio nacional. Estos salvadoreños mantienen un identidad salvadoreña pero modificada por el contexto distinto en el que se han desarrollado. Son identidades en construcción puesto que las comunidades salvadoreñas en cl exterior son relativamente jóvenes. En Cálgary, Canada la comunidad salvadoreña es muy joven y se encuentra en formación en relación a sus integrantes y las relaciones con el contexto canadiense que viven ${ }^{17}$

Estegrupo en especifico son hombres de mediana edad, que aprendieron a sobrevivir en un ambiente hostil, en el que tuvieron que cambiar su sistema de normas y valores para habituarse al modo de vida nuevo.

En la charla de bienvenida que of rece el programa, tienen un apartado para este grupo de "muchachos" deportados. Les informan de los cambios que El Salvador ha llevado a cabo como pais. Se les informa de que el pais ya no es el mismo que hace veinte o veinticinco años. La imagen que ofrecen en conscientemente positiva y los cambios de los que hablan por supuesto que son reales, ya que efectivamente el pais dejó de estar en guerra y existe un proceso democrático estable. Por supuesto estoscambios no se comparan con los derechos de los que gozan incluso los inmigrantes en el país del Norte, autoproclamado como el país de la libertad y de la democracia.

A pesar de los años viviendo en los Estados Unidos. con todolo que lleva aparejado, ya no pueden regresar. Todos piensan en volver, sobre todo porque al llegar aquí han 
perdido su status socio-económico y todas sus pertenencias conseguidas y por supuesto todas sus relaciones familiares $y$ amistades. A pesar de ello no pueden regresar bajo amenaza de que se les acuse de una pena mayor. Por lo tanto se encuentran en el momento de bajar del avión ante una encrucijada vital de no fácil solución, sobretodo porque la readaptación a la sociedad salvadoreña es difícil entre otros motivos por la edad productiva en la que ellos se encuentran.

Hay un tipo de deportados que han sido devueltos a su pais de origen por haber cometido delitos graves. Son los menos y significan alrededor de un 15 por ciento de los deportados llegados al aeropuerto de Comalapa. Con datos de abril del 2001 , de las 7 mil 393 personas atendidas, 927 venían por razones de faltas graves. $Y$ al igual que sus compañeros a no ser que tengan asuntos pendientes con la justicia en territorio nacional la PNC los deja salir libres del aeropuerto sin posibilidad de mantenerlos retenidos.

Por haber cometido delitos graves como asesinatos o violaciones han estado retenidos algunos años incluso en prisiones federales. Algunos de ellos visten las ropas que llevaban en las prisiones.

No existen estudios al respecto de la asociación directa entre los deportados que han comerido actos graves y la extensión de la delincuencia en el país. Algunos deportados aparecen en actos delictivos tras su llegada a El Salvador. En ese sentido, sería interesante un estudio más amplio para verificar el entramado delincuencial salvadoreño y sus relaciones con la delincuencia organizada con otros paises

En este grupo de deportados que han cometido delitos graves cabe destacar un grupo específico con una

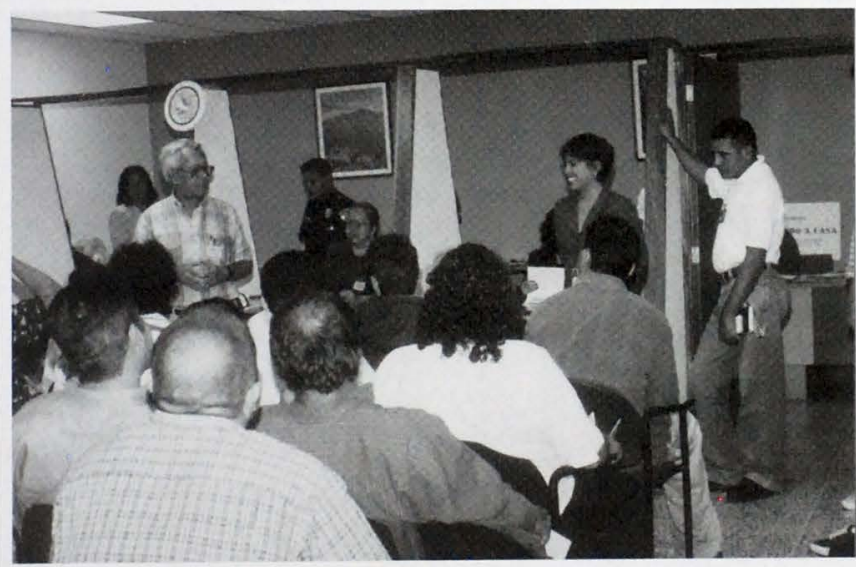

característica peculiar. Se trata de los jóvenes de la generación 1.5 Son los salvadoreños llevados a Estados Unidos por sus padres y/o familiares cuando eran niños y han crecido en los barrios de latinos de este país. Sus imágenes de El Salvador son muy lejanas y sus visitas a éste han sido en muchos casos esporádicas. Se sienten más cómodos hablando inglés que español. No reconocen la sociedad salvadoreńa como suya puesto que no crecieron aquí, para ellos el impacto es casi total añadiendo además que no se reconocen salvadoreños.

Sus problemas con las drogas y la delincuencia juvenil que azota los barrios latinos les lleva por un camino que termina en el aeropuerto de Comalapa.

Algunos de éstos no forman parte de las estadísticas del programa Bienvenido a Casa puesto que llegaron por sus propios medios o el de sus familiares en un intento de evitar la justicia estadounidense por algún acto delictivo cometido. Estos tambićn son retornados involuntarios aunque no hayan sido deportados directamente por las autoridades correspondientes. Con este grupo de la generación 1.5 la readaptación es más difícil porque nunca estuvieron adaptados y además retornan marcados por la cultura de la juventud americana, con pendientes, tatuajes, gestos, expresiones y actitudes que no son muy bien aceptadas por la sociedad salvadoreńa. Ellos se sienten extranjeros en su propio pais y son excluidos como tales.

Los jóvenes de la generación 1.5 pertenecientes a las pandillas en los Estados Unidos trasladaron su experiencia violenta en las calles de las ciudades estadounidenses, en especial de Los Ángeles, a El Salvador transformándose en maras. Es sabido que la Mara Salvatrucha y la del Barrio Dieciocho vinieron importadas con jóvenes pandilleros a las calles de la ciudad capital.

En estos jóvenes se condensan tres procesos de exclusión social. El primero con la salida del pais, vinculado a la pobreza y la falta de oportunidades del grupo familiar al que pertenece. Las vivencias en las ciudades de los Estados Unidos están marcadas por la xenofobia, el racismo y la discriminación social por su origen latino. Éste es un punto fundamental para entender el proceso de formación de las pandillas en

Febrero-Marzo 2002, $\mathrm{N}^{\circ} .23$ 
los Estados Unidos. Este es el segundo proceso de exclusión social. El tíltimo lo viven a su regreso al pais de origen, a El Salvador, cuando son extranjeros en la tierra que les vio nacer ${ }^{18}$.

Algunos de los jóvenes deportados de esta forma afirman la intención de "calmarse" en su vida violenta al llegar al país ya que algunos ya han iniciado el proceso en las cárceles donde estaban recluidos. Sin embargo, el proceso de exclusión social, la falta de oportunidades, el impacto que les produce el desconocimiento de su país los lleva en muchos casos a reiniciarse en la "vida loca", sabiendo que en el mundo violento salvadoreño adquieren un status mayor por venir de las calles de los Estados Unidos.

Johnny, ya estaba calmado a su llegada al pals como deportado. Pero al llegar se juntó con un grupo de deportados venidos también del pais del Norte. Compartian muchos aspectos en común que no tienen con el resto de la sociedad salvadoreña. Fuera de este pequeño grupo sentía la discriminación en las miradas a su cabeza tatuada y su pelo cortísimo o a los tatuajes evidentes en sus brazos y cuello. La forma de vestirse también es distinta a los ciudadanos de a pie que caminan por las calles de San Salvador. Recayó en su vida violenta y de consumo de drogas con sus compañeros. Fue el único que finalmente se quedó, el resto, se volvió a marchar a los Estados Unidos y no sabe cuál fue el destino de esros. Johnny finalmente retomó la idea de calmarse hace unos años y en estos momentos ayuda a la rehabilitación de los pandilleros

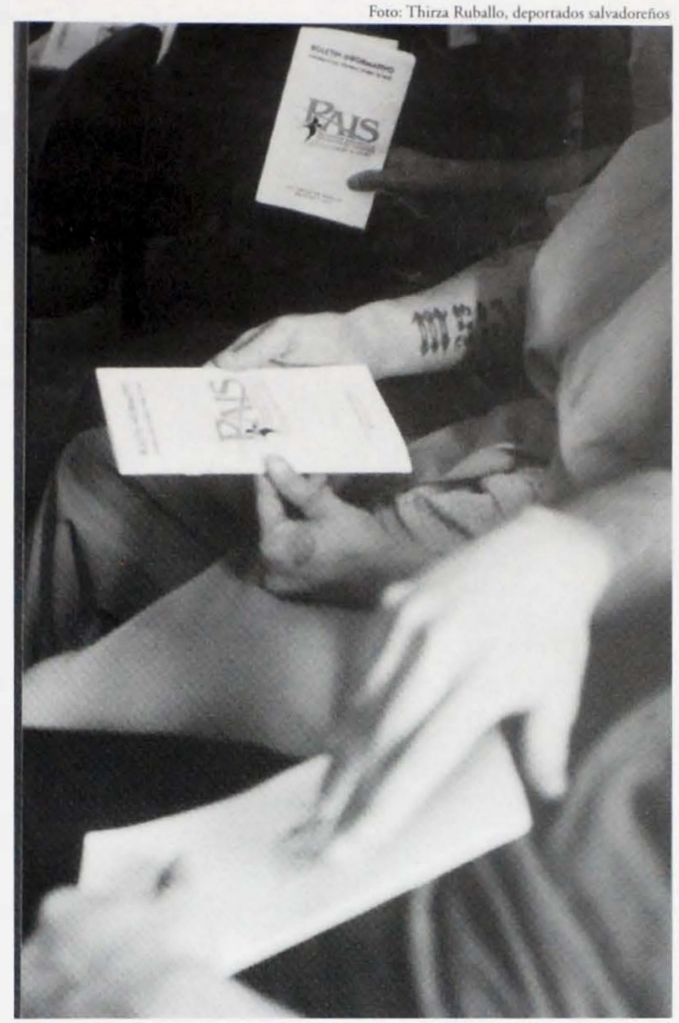
salvadoreños en una asociación llaunada Homies Unidos. En dicha asociación los pandilleros luchan por transf ormar las maras en un apoyogrupal para sus integrantes pero erradicando las formas violentas.

Johnny es una influencia positiva para el abandono de la vida loca de otros pandilleros. En los locales de Homies Unidos es posible ponerse en contacto con otros deportados de la generación 1.5. Johnny apoyó a Willy en su decisión de quedarse y empezar a construir un sueño: montar un lugar de mecánica de carros al escilo de los Estados Unidos. Por el momento es sólo un sueño pero ha abandonado todas las acciones violentas que lo trajeron a el Salvador. Jonathan no vino deportado por las autoridades migratorias estadounidenses. Fue enviado por sus familiares inmediatamente después de cometer un delito grave y en aras de escapar de la justicia. No es el único, otros jóvenes han retornado de este modo pero también hemos de considerarlos deportados porque suf ren los mismos procesos de exclusión social que el resto, además de cumplir con la

característica de no haber retornado voluntariamente. En estos casos, El Salvador significa, contradictoriamente al resto de las vivencias de los demás deportados, tambićn la tierra de la libertad. Esto se evidencia sobre todo con los jóvenes de la generación 1.5 que son enviados por sus familiares para huir de la justicia estadounidense. A pesar de todos los problemas El Salvador es una via alternativa con la ayuda necesaria, por supuesto, de los que se quedaron en Estados Unidos. La posibilidad de ser condenado a prisión es suficiente motivo para intentar sobrevivir en esta sociedad. La ayuda de los familiares, sobre todo los padres, es fundamental. Esto no implica que no añoren su vida en la sociedad americana en donde crecieron. Sin embargo, su propia experiencia les obliga a reflexionar y contestan de forma contradictoria. Johnny y Jonathan ambos quisieran regresar a los Estados Unidos ahora que ya estin calmados. pero no sería el lugar escogido para criar a sus hijos. La razón es la cantidad de "vicios" que los puede llevar al mismo camino de las pandillas y de ahí al consumo de drogas 


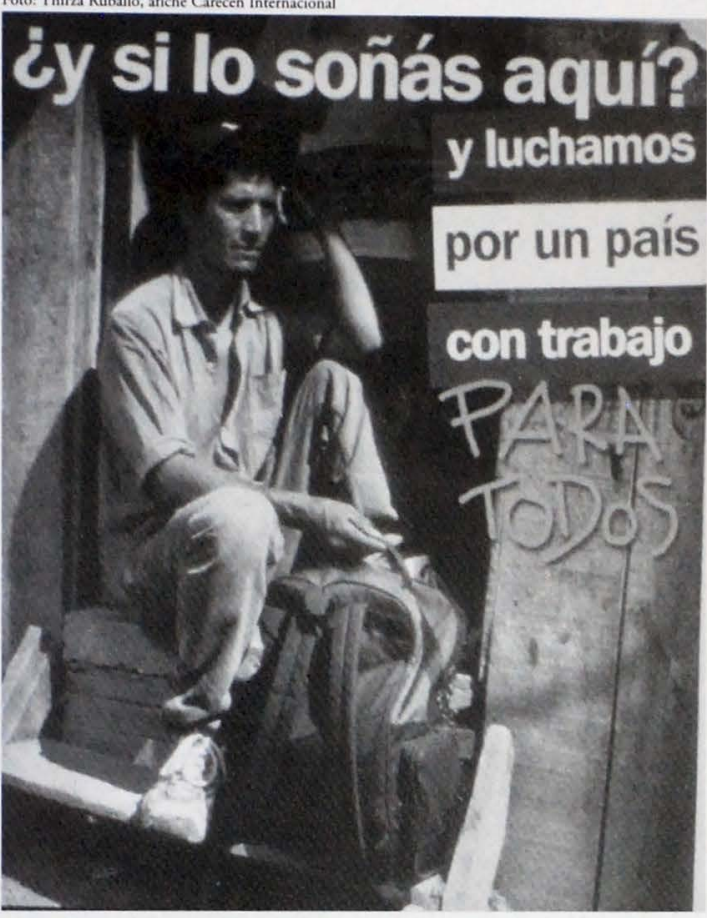

si de nuevo es deportado su pena se agrava. Algunos intentan su regreso por la vía legal, solicitando la revisión de sus condenas o piden un perdón. Esta desde luego es la vía más lenta.

También hay personas que llegan a El Salvador en mejores condiciones de las que se fucron y con el paso del tiempo logran readaptarse al pais. La experiencia en Estados Unidos y su condición bilingüe inglésespañol, además de la disciplina de trabajo adquirida, les hace en algunas ocasiones más comperentes para algunos puestos de trabajo que los locales. Son los menos, pero hay casos, como profesores de inglés, en los grandes hoteles de San Salvador, como chefs.

Han aprendido una nueva forma de trabajar al estilo de los Estados Unidos, basada en la calidad del servicio y de la producción y además tienen una herramienta valiosa en la sociedad salvadorcña, el dominio del idioma inglés.

Es necesario que socialmente aceptemos a los retornados involuntarios como parte del proceso de migraciones en El Salvador. Hay que invalidar la imagen social que identifica a los retornados involuntarios como delincuentes y apoyarlos en su proceso de integración en la sociedad.

y prácticas violentas. Creen que El Salvador es sucio, que no se respera a las personas y que se gana muy poco. Paradójicamente tras una infancia llena de irrespeto por la vida, una vez son adultos, claman por ese derecho que creen que aqui no se tiene en cuenta.

La exclusión social es quizás el problema fundamental que hay que abordar con el tema de los deportados. Pero la exclusión social no afecta únicamente a este grupo sino a una parte excesivamente amplia de la sociedad salvadoreña. De hecho si todas las personas tenemos derecho a emigrar también todas las personas tenemos derecho a no vernos obligados a migrar. En el caso concreto de los deportados existe un porcentaje amplio que regresa de nuevo a los Estados Unidos. La razón es que no encuentran lugar donde seguir con sus vidas. A pesar de todos los cambios ocurridos en El Salvador no son suficientes como para integrar a estas personas en las mismas condiciones en las que se encontraban en el país del Norte. Por cllo, de la misma forma por la que abandonaron todo, para iniciar una nueva vida, tras la deportación lo intentan de nuevo. A pesar de codos los posibles riesgos que conlleva no sólo salir del país como indocumentado con las dificultades del camino, sino porque

Por otra parte, hay que incentivar el conocimiento de otros aspectos de las migraciones, sobre todo los que tratan de arrojar luz sobre las consecuencias socio-culturales de este proceso de cambio que permea como hemos visto todos los aspectos de la vida salvadoreña.

Hasta el momento hay abundancia de las consecuencias de las migraciones pero en pais de destino, habitualmente países con una larga tradición académica preocupada por los cambios socioculturales que observan en la sociedad. En países como El Salvador no existe una tradición académica preocupada por los cambios desde el punto de vista social y cultural y tampoco existe el suficiente interés o capacidad para la financiación de proyectos que aborden temas de investigación migratorios. Son necesarios en todo caso como observatorio de los procesos de cambio social en este pais centroamericano.

Para todo ello haria falta una politica migratoria estatal combinada con la centroamericana que trate el fenómeno de las migraciones más humanamente y como algo más que una vía de entrada de remesas.

Febrero-Marzo 2002, $\mathrm{N}^{\circ} .23$ 


\section{CITAS}

'WhinschuhThomas, 1999.

Whinschuh Thomas, Porque se van San Salvador. Heinrich Boll, 1999

'Lungo Mario, 1996 Ap.25.

"Garcia Ju:un Joste, 1996 p.22-23.

'Garcfa Juan José. 1996 p.25.

${ }^{6} \mathrm{Lil}$ Prensa Gr stica, p.7b.

'La Prensa Gráfica, p.6b.

'La Prensa Grática, p.7b.

${ }^{9} \mathrm{Garcla}$ Juan José, 1996 p.32.

${ }^{10} \mathrm{Garcia}$ Juan José, 1996 p.30.

"García Juan José, 1996 p.31.

"Lungo Mario y Elchoff Kay. Migración Internacional y Desarrollo, el caso de Santa Elena, Usulután, p.S.

"Carecen Internacional parn los que no llegaron, un sueño hecho cenizas, 2000.

${ }^{14}$ Colato José y Aguilar Jesús. Carecen Internacional, Nada puede detener el sueño de los migrantes, p.S.

1"Perdomo José y Colato José, las migraciones y deportaciones, p.14. Nada puede detener el suevio de los migrantes.

${ }^{16}$ López Miguel y Colato José, el recibimiento de los deportados en El Salvador, p.5. Nada puede detener el sueño de los migrantes.

'Lara Carlos, Salvadoreños en Cálgary, el proceso de configuración de un nuevo grupo étnico San Salvador, Concultura, 1994, p.107-117.

1*Smuct Marcela y Mir anda Jenny, el fenómeno de las pandillas en El Salvador. San Salvador, UNICEF-FLACSO, 1998, p.36.

\section{BIBLIOGRAF(A}

BOLETIN INFORMATIVO. Información general sobre iu pais. PAIS. Programa de atención a los Inmigrantes salvadoreños. San Salvador, CRSOIM-Gobierno de El Salvador,

CASTILLO, MANUEL Ángel y PALMA; Silvia Irene, La emigración internacional en Centroamerica: una revisión de tendencias e impactos, Guatemala, FLACSO, Programa de Guatemala, 1996.

GARCLA; Juan José, Remesas y relaciones sociales locales: el caso de San Isidro. San Salvador, FLACSO Programa El Salvador, 1996.

HERRAIZ LOPEZ, Luis León, Migrantes. Tejedores de Esperanza, Guatemala, Centro de Atención al Migrante.

LARAMARTINEZ, Carlos Benjamín. Salvadoreños en Calgary Elproceso de con figuración de un nuevo grupo ésnico. San Salvador, Concultura, 1994.
LUNGO, Mario, Migración internacional y desarrollo TOMO I y II. San Salvador, FUNDE, 1997

LUNGO; Mario, Migraciones internacionales. Remesas e impacto en las ciudades en Alternativas para el Desarrollo. $N^{\circ} 17-18-19-20-21$. Febrero, abril, ma yor, junio de 1994, San Salvador, FUNDE pp. 21-24.

LUNGO, Mario, Politicas migratorias y desarrollo, Alternativas para el Desarrollo $N^{\circ} 60$, sepriembre/octubre 1999. San Salvador, FUNDE.

LUNGO, Mario, Centroamérica: Migración Internacional y Políticas Migratorias, Alternativas para el Desarrollo $n^{\circ} 47$, julio/agosto 1997. San Salvador, FUNDE, pp. 13-19.

LUNGO. Mario y Eekhoff, Kay. Migración lenernacional y Desarrollo: El caso de Sanca Elena, Usulucán, Alsernativas para el Desarrollo $n^{\circ} 28$, abril 1995. San Salvador, FUNDE, pp. 1.8.

LUNGO; Mario y KANDEL, Susan (comp), Transformando El Salvador. Migración, Sociedad y Cultura, San Salvador, FUNDE, 1999.

LUNGO, Mario y KANDEL: Susan, "Cambios socioculturales en ciudades pequeñas provocadas por la migración inceenacional”. en LUNGO, Mario y KANDEL. Susan (comp) Transformando El Saluador. Migración Sociedad y Cultura, San Salvador, FUNDE, 1999. pp. 171-220

LUNGO, Mario, "La construcción de la ciudadanía social ante la migración incernacional" en LUNGO. Mario y KANDEL. Susan (comp) Trans formando El Salvador. Migración Sociedad y Cultura. San Salvador. FUNDE, 1999, pp. 9-38.

MARMORA; Lelio. La definición de las politicas de migraciones internacionales. Seminario Taller sobre Las migraciones en El Salvador pers pecrivas y propuestas para la acción. San Salvador, diciembre de 1995.

MÁRMORA, Lelio, El fenómeno mi gratorrio regional en América Central y del Norte. Politicas y Gobernabilidad. Conferencia Regional de Migración. Puebla, 11 al 14 de marzo de 1996

NADA PUEDE detener el sueño de los migrantes. Sueños truncados, San Salvador, CARECEN, 2000.

PARA LOS que no llegaron un sueño hecho cenizas: Migrantes y deportados en la fromtent Guaternala-Mbxico, CARECEN INTERNACIONAL.

La PRENSA GRAFICA. Ecuatorianos en El Salvador: La otra politica migratoria. Departamento 15. San Salvador, 3 de mayo de 2001 año $1 N^{\circ}$ 11.

RODRIGUEZ, América, "Migración sociedad y cultura en Nueva Concepción. Una revisión desde la etnografia", en LUNGO. Mario y KANDEL, Susan (comp) Trans formando El Salvador. Migración Sociedad Cultura, San Salvador, FUNDE, 1999 PP 221-270.

SMUTT. Marcela y MIRANDA; Jenny Lissetre, El fenómeno de las pandillar en El Salvador, San Salvador, UNICEF.FLACSO, 1998.

WINSCHUH, Thomas, ¿Porquése van?. San Salvador, Ediciones Heintich Böll, 1999.

ZILBERG, Elana y LUNGO, Mario, "¿Se han vuelto haraganes? Jóvenes salvadoreños, migración e identidades laborales", en LUNGO, Mario y KANDEL. Susan (comp) Transformando El Salvador. Migración Sociedady Cultura. San Salvador, FUNDE, 1999. entorno

entorno

entorino

entorno

entorno

entorno

entoring

entorno

entorno

entorno

entorno

entorno

entorno

entorno

entorno

entorno

entorno

entorno

entorino

entorno

entorno

entorno

entorno

entorno

entomo

entorno

entorno

entorne

entorno

entorno

entorno

entorno

entorno

entorno

entorno

entorno

entorno

entorno

entomo

entorno

entorno

entorno

entorno

entorno

entorno

entorno

entorno

entorno 